\title{
The influence of wave groups and wave-swash interactions on sediment transport and bed evolution in the swash zone
}

\author{
José M. Alsina ${ }^{\mathrm{a}, \mathrm{c}, *}$, Joep van der Zanden ${ }^{\mathrm{b}}$, Iván Cáceres $^{\mathrm{c}}$, Jan S. Ribberink ${ }^{\mathrm{b}}$ \\ ${ }^{a}$ Department of Civil and Environmental Engineering, Imperial College London, South \\ Kensington Campus, SW7 $2 A Z$. \\ ${ }^{b}$ Marine and Fluvial Systems group, University of Twente, Drienerlolaan 5, 7522 NB \\ Enschede, The Netherlands. \\ ${ }^{c}$ Laboratori dEnginyeria Marítima, Universitat Politecnica de Catalunya, C. Jordi \\ Girona, 1-308034 Barcelona, Spain.
}

\begin{abstract}
Large scale laboratory measurements of sediment dynamics in the swash zone are presented. Two bichromatic wave group conditions were generated, having the same energy content but different wave group period $\left(T_{g}=15.0 \mathrm{~s}\right.$ and $27.7 \mathrm{~s}$ ). For the shortest wave group, due to bore focussing, the shoreline fluctuates predominantly at the $T_{g}$ time scale, showing a large runup and the presence of wave-swash interactions with strong momentum exchange. In contrast, for the longer wave groups, the swash excursion is dominated by the individual waves. The uprush generally promotes onshore sediment advection with consequent erosion at the rundown location but accretion close to the runup. On the contrary, the backwash promotes seaward sediment advection and accretion at the rundown location. The presence of repeated wave-swash interactions modifies these patterns slightly. A wave overrunning a previous uprush promotes a reduction in onshore sediment advection while weak wave-backwash interactions reduce seaward advection. Consequently, the measured sediment dynamics shows stronger intra-swash cross-shore sediment advection for the swash events produced by the short wave groups. Measurements of the sheet flow layer near the shoreline show that for the shortest wave groups the vertical structure of the concentration
\end{abstract}

\footnotetext{
${ }^{*}$ Corresponding author

Email address: jose.alsina@upc.edu (José M. Alsina )
} 
is influenced by horizontal advection, leading to large sheet-flow layer thickness. However, for the longer wave groups, the local vertical exchange of sediment in the sheet-flow layer is dominant, with the presence of a pick-up and mirroring upper layer similar to oscillatory sheet-flow measurements. These results reaffirm the important effects of the wave group structure and the wave-swash interactions on the swash zone sediment dynamics and beach face evolution.

Keywords: Swash zone, bed level changes, sediment transport, bichromatic waves, large-scale wave flume, sediment advection, wave-swash interactions

\section{Introduction}

The swash zone is the region that connects the emerged part of the beach and the surf zone. The swash zone is characterized by hydrodynamic and sediment transport processes that are highly dynamic and depend strongly on the energy arriving from the inner surf zone and the beach-face morphology. Incident energy arrives at the shoreline at a number of different scales including tidal water motions, low-frequency motions (typical wave periods between 20-200 s), short waves (wind and swell with periods between 3-20 s), turbulent motions due to waves collapsing at the shoreline, bed friction, or interactions between the swash event and successive incoming waves. These fluid motions, in turn, interact with the bed and are powerful agents of sediment transport.

It is widely acknowledged that an important amount of the nearshore sediment transport occurs within the swash region (Masselink and Puleo, 2006). Understanding the sediment dynamics in the swash zone is of fundamental importance not only because it shapes the beach-face morphology (dune erosion, beach-face recovery, building of the berm, alongshore shoreline evolution) but also because of its potential influence on the surf zone dynamics as a whole (e.g. Brocchini and Baldock, 2008; Alsina et al., 2012; Martins et al., 2017). Because of its importance, the swash zone has attracted significant research attention; the latest advances are summarized in recent review works (Masselink and Puleo, 2006; Brocchini and Baldock, 2008; Chardon-Maldonado et al., 2016).

Sediment transport measurements in field and laboratory conditions have been obtained from sediment traps (Masselink et al., 2009; Alsina et al., 2009; O'Donoghue et al., 2016), from co-located velocity and concentration 
sensors (Aagaard and Hughes, 2006; Alsina and Caceres, 2011; Masselink et al., 2005; Puleo et al., 2000) or indirectly obtained from bed level measurements (Blenkinsopp et al., 2011). Measured sediment transport using sediment traps in laboratory conditions for single swash events have shown that, for large sediment sizes, sediment fluxes during the uprush are maximum (landward) at the moment of bore arrival, then decay and become zero at flow reversal (O'Donoghue et al., 2016). Backwash sediment transport is of smaller magnitude but of longer duration. For finer sand particles, suspended sand trapping by turbulent vortices becomes more important, and the contribution of suspended sediment fluxes to the total sediment transport during the uprush is more significant (Alsina et al., 2009).

Using collocated sediment concentration and velocity sensors, large sediment concentration and sediment fluxes have been measured at the beginning of the uprush and last stage of the backwash (Masselink et al., 2005, 2009; Butt and Russell, 1999). It has been suggested that the net sediment transport in the swash zone is a small difference between two large quantities (uprush vs backwash). Using measurements of inter-swash bed level changes, Blenkinsopp et al. (2011) showed that the majority of swash events produce very little net sediment transport while a few random swash events mobilized large amounts of sediment. These events were associated to interacting swash events (Blenkinsopp et al., 2011). Controlled laboratory experiments by Alsina et al. (2012) and Caceres and Alsina (2012) reaffirmed the importance of swash interactions for the measured beach evolution and sand transport.

However, sediment traps and inter-swash measurements of bed evolution do not provide time--dependent information, with the exception of O'Donoghue et al. (2016). Collocated measurements, on the other hand, also present several shortcomings: i) concentration and flow sensors are typically placed a few centimeters above the bed, hence neglecting the major sediment transport contribution very close to the bed, ii) they generally do not capture the initial stage of the uprush and final stage of the backwash due to noise at the air-water interface and because of the thin layer of water during the backwash and iii) due to rapid bed evolution, the elevation of the fixed sensor with respect to the bed changes in time, hence increasing the uncertainty in sediment concentration measurements.

These issues have recently been overcome by applying conductivity-based probes to measure time-dependent sediment concentration very close to the bed (bed-load or sheet flow sediment transport) and bed evolution in the 
swash zone (Lanckriet et al., 2013, 2014; Puleo et al., 2014, 2016; van der Zanden et al., 2015). Sheet flow is a sediment transport mode that occurs during highly energetic flow conditions relative to the sand particle weight. When near-bed velocities are sufficiently high, sand is mobilized into a highconcentration (100 to $1600 \mathrm{~g} / \mathrm{L}$ ) sheet flow layer with a typical thickness of 10 to 100 times the grain diameter (Ribberink et al., 2008). Sheet flow dynamics have been studied extensively in uniform oscillatory flows (oscillatory flow tunnels) (O’Donoghue and Wright, 2004; Ribberink et al., 2008) and in large scale wave flumes under non-breaking skewed waves (Schretlen, 2012; Dohmen-Janssen and Hanes, 2002, 2005) and asymmetric shoaling and breaking waves (Mieras et al., 2017; van der Zanden et al., 2017). In such conditions, the sheet flow vertical structure is divided into two layers: a pickup/deposition layer, below the still bed level, and an upper sheet flow layer above the still bed level (Ribberink et al., 2008). During a wave cycle, the bed shear stress by orbital velocity drives a vertical exchange of sediment between the pick-up and upper sheet flow layers. The sediment concentration decreases (increases) in the pick-up layer while it increases (decreases) in the upper sheet flow layer during high (low) flow velocity, hence leading to a mirroring behaviour of sediment concentration in the pick-up and upper sheet flow layers.

Because of the large flow velocities during initial uprush and the final stage of the backwash, sheet flow sediment transport has been highlighted as an important contributor to swash zone sediment transport (Masselink and Puleo, 2006; Puleo et al., 2016). Nevertheless, sheet flow measurements in the swash zone are more scarce due to the difficulties of obtaining high-quality measurements in the alternately emerged/submerged swash region. Very recently, vertical concentration profiles during isolated random swash events have been measured using a Conductivity Concentration Profiler (CCP)(Lanckriet et al., 2013, 2014; Puleo et al., 2016), showing a similar vertical distribution to those observed for oscillatory sheet flows (Lanckriet et al., 2014). On the other hand, vertical sediment concentration profiles measured by van der Zanden et al. (2015) during a wave-group-induced swash cycle showed a distinct behavior where a pick-up layer was not evident due to a large influence of horizontal sediment advection. The latter shows that the sheet flow layer in the swash zone is not always controlled by local velocity forcing, but instead, may also be affected by the sand influx from adjacent locations (van der Zanden et al., 2015). This marks a notable difference from oscillatory sheet flows in oscillatory flow tunnels and under non-breaking 
waves. Measurements have further suggested that pressure gradients and bore turbulence may increase the sheet flow layer thickness in the swash zone (Lanckriet and Puleo, 2015; van der Zanden et al., 2015).

Many field and laboratory data have largely focused on single discrete swash events by either isolating individual swash events within a random time series (Puleo et al., 2014, 2016) with ensemble averaging between similar single swash events, or by laboratory experimentation using solitary waves (Alsina et al., 2009) or dambreak-type swash events (Barnes et al., 2009; O'Donoghue et al., 2016; Wu et al., 2016). The latter is an idealized situation in which wave-swash interactions are not considered. Waveswash interactions (Caceres and Alsina, 2012; Hughes and Moseley, 2007) (sometimes termed swash-swash interactions) occur when waves arrive at the shoreline during a preceding uprush, hence adding momentum ("wavecapture") or during the preceding backwash, inducing opposing momentum (termed "wave-backwash interaction"). The type and degree of wave-swash interaction is highly important for swash zone hydrodynamics, as the momentum of the incident wave affects the shoreline motion (Erikson et al., 2005) and swash velocities (Chen et al., 2016; Pujara et al., 2015), but also for swash zone sediment transport where certain wave-swash interactions events have been shown to promote large sediment re-suspension events and offshore sediment transport (Alsina et al., 2012; Blenkinsopp et al., 2011; Caceres and Alsina, 2012).

Despite previous efforts, the physical processes that drive bed evolution in the swash zone are still not fully understood. In particular, the effects of wave group structure and wave-swash interactions on sheet flow dynamics, sand suspension and bed evolution at intra-swash time scale have not been examined to full extent. Therefore, this paper presents an analysis of time-dependent bed evolution and sediment concentration and flux during controlled swash events in a large-scale wave flume. Measurements were obtained for two bichromatic wave conditions with equal energy but varying wave group period in order to specifically examine the influence of the wave group structure and wave-swash interactions on sediment transport and bed evolution.

The paper is organized as follows. The experimental setting and data acquisition are explained in section 2. The morphologic change of the beach profile within the swash zone for both wave conditions is presented in section 3, followed by a description of the wave group evolution across the surf and swash zones in section 4 . The time-dependent bed evolution and sus- 
pended sediment concentration for different wave groups will be explained in section 5, followed by a description of the sheet flow dynamics in section 6 . Finally, the discussion and conclusions of the data analysis will be presented in sections 7 and 8 .

\section{Experimental procedure}

\subsection{Experimental set up}

The experimental data presented in this study were obtained at the CIEM large scale wave flume at Universitat Politecnica de Catalunya (UPC), Barcelona during the HYDRALAB-IV transnational access project CoSSedM (Coupled High Frequency Measurement of Swash Sediment Transport and Morphodynamics). The experimental setup has been described extensively in previous publications (Alsina et al., 2016; van der Zanden et al., 2015); a brief summary is presented in this section.

The mean initial beach profile and instrument locations in the inner surf and swash zones are illustrated in Figure 1. The vertical elevation $z$ is defined positive upwards from the still water level (SWL). Two types of cross-shore coordinates are illustrated in Figure 1, both defined positively towards the beach: a fixed coordinate $X_{a}$ with the origin located at the wave paddle, and a coordinate $X$ with the origin at the initial shoreline location which varies with the working water depth. The $X$ coordinates for the main wave conditions presented in this work are included in Figure 1.

An initial 1:15 plane-sloping beach was built with commercial well-sorted sand with a medium sediment size of $d_{50}=0.25 \mathrm{~mm}\left(d_{10}=0.154 \mathrm{~mm}\right.$ and $d_{90}=0.372 \mathrm{~mm}$ ) and a measured sediment settling velocity of $w_{s}=0.034$ $\mathrm{m} / \mathrm{s}$. Various instruments were deployed from the flume side-walls to measure water surface elevation (resistive wave gauges, WG, pore pressure transducers, PPT, and acoustic wave gauges, AWG), velocities (acoustic Doppler velocimeters, ADV) and sediment concentration (optical backscatter sensors, OBS) along the flume. The cross-shore locations with respect to the wave paddle and the vertical positions with respect to the initial bed level (when relevant) of all installed instrumentation are presented in Table 1.

Horizontal velocity and suspended sediment concentrations were measured with collocated OBS and ADV sensors at four different cross-shore locations within the swash zone and at vertical elevations between 3 and 5 $\mathrm{cm}$ above the bed (see Table 1). The cross-shore spatial resolution ranged between 0.45 and $1.6 \mathrm{~m}$ (see Figure 1). The vertical location of ADV and 
OBS sensors with respect to the bed is verified at the beginning of each hydrodynamic run and sensors are repositioned at the beginning of each run to ensure the same vertical elevation with respect to the evolving bed level.

In addition, two Conductivity Concentration Measurement $\left(\mathrm{CCM}^{+}\right)$tanks were installed at two cross-shore locations within the swash zone to measure bed level changes and sediment concentrations in the sheet flow layer. The $\mathrm{CCM}^{+}$tanks were buried in the beach such that the conductivity probes targeted the water-bed interface from underneath. Technical details, settings and performance characteristics of the $\mathrm{CCM}^{+}$tanks can be found in Section 2.3. The project aimed to obtain measurements with a high spatial resolution. However, due to their size, the installation of the $\mathrm{CCM}^{+}$tanks was highly time-consuming (around three days). In order to increase the number of $\mathrm{CCM}^{+}$cross-shore measurement locations in the swash zone, some experimental wave conditions were repeated with two different water depths. Alsina et al. (2016) showed that repeated wave conditions with varying water depth resulted in highly similar beach hydrodynamics and beach profile evolution when the hydrodynamic variables and the bed level are plotted in cross-shore coordinates relative to the initial location of the shoreline. The latter is defined as the intersect between the still water level (SWL) and the initial bed profile.

\subsection{Wave conditions}

Wave conditions consisted of bichromatic wave groups with different wave group periods but with constant wave energy and incident wave energy flux (Alsina et al., 2016). The wave conditions in the present analysis and the corresponding working water depths are found in Table 2. The present study focuses on conditions BE1 and BE4 that have the largest differentation in terms of wave group period $T_{g}: T_{g}=15 \mathrm{~s}$ for BE1 and $T_{g}=27.7 \mathrm{~s}$ for BE4. Both wave conditions were generated for two working water depths (annotated through additions '_1' and '_2'). The initial shoreline positions for the different wave conditions are: $X_{a}=75.56 \mathrm{~m}$ (BE1_1), $75.30 \mathrm{~m}$ (BE1_2), $75.36 \mathrm{~m}$ (BE4_1) and $74.76 \mathrm{~m}$ (BE4_2) (Figure 1).

It is important to note that for BE4, all successive wave groups in the time series are identical, meaning that the wave group period is the same as the repetition period $\left(T_{R}\right), T_{R}$ being defined as the time at which the phase of an individual wave within the group repeats exactly (Baldock et al., 2000). However, for wave condition BE1 a wave group repeats exactly every 13 wave groups and $T_{R}=195 \mathrm{~s}$. 
For each wave condition the same experimental procedure was followed. Starting from the same plane-sloping beach profile, eight hydrodynamic runs (seven for BE1_1) of 30 min of waves were generated for each wave condition. The bed profile was measured prior to each experiment and after each 30min of wave action using a wheeled bottom profiler (specifications found in Baldock et al. (2011)), yielding nine bed profile measurements for each 240min. experiment (eight profiles and $210 \mathrm{~min}$ for BE1_1). The flume was then drained and the initial bed profile was manually restored. The average variability between the initial beach profiles was approximately $1 \mathrm{~cm}$.

\section{3. $C C M^{+}$measurements}

Details of the $\mathrm{CCM}^{+}$system, signal processing and application of the $\mathrm{CCM}^{+}$in the swash zone can be found in van der Zanden et al. (2015), a brief resume of the system is given here. $\mathrm{CCM}^{+}$tank 1 consists of 3 conductivity probes: two of them are paired and located on the same vertical rod (probes 1-2) while probe 3 is located on a separate, second rod. CCM probes 1-2 are aligned in cross-shore direction allowing the computation of sediment particle velocities using a cross-correlation technique (McLean et al., 2001). A second CCM tank consists of a single conductivity sensor on a vertical rod (probe 4). The two tanks are buried in the beach and the probes measure the electrical resistance of the water-sediment mixture over a sampling volume that extends vertically over approximately $1 \mathrm{~mm}$. The measured resistance is translated to a voltage, $V_{m}$, which relates to the sediment volume concentration $C\left(\mathrm{~m}^{3} / \mathrm{m}^{3}\right)$ as (van der Zanden et al., 2015):

$$
C=\left(1-\frac{V_{0}}{V_{m}}\right) f_{c a l}
$$

where $V_{0}$ is the reference voltage for clear water and $f_{\text {cal }}$ is a dimensionless calibration factor that is usually close to unity. Both $V_{0}$ and $f_{\text {cal }}$ depend on probe characteristics and in-situ water conditions. Before the start of an experiment, the voltages in clear water and in a loosely packed sand bed are measured in order to calibrate the measurements.

The absolute vertical positions of sensors $1,2,3$ and $4\left(z_{1-2}, z_{3}\right.$ and $z_{4}$ ) are controlled with sub-mm accuracy and are continuously recorded. An internal loop allows the system to continuously track a specified conductivity value (concentration) by automatic vertical repositioning of the probes. By

selecting a target voltage corresponding to a concentration of $0.30 \mathrm{~m}^{3} / \mathrm{m}^{3}$, the probes can automatically track the bed-water interface, i.e. provide a 
continuous measurement of the bed level $z_{\text {bed }}(t)$. Because of limitations in the tracking system, the bed elevation $z_{\text {bed }}(t)$ is measured with a temporal lag of approximately one second. Hence, the system can measure bed level changes that occur at short-wave-averaged time scales $(\approx 5 \mathrm{~s})$ and longer, but it cannot directly measure the intra-short-wave bed level fluctuations (van der Zanden et al., 2015). However, by generating repeating swash events followed by ensemble-averaging of $C\left(z^{\prime}, t\right)$ measurements (with $z^{\prime}=z-z_{\text {bed }}$ ), the bed elevation at intra-wave time scales can be recovered by computing the pivot point of the sheet flow layer (O'Donoghue and Wright, 2004; van der Zanden et al., 2015).

During the present experiment, $\mathrm{CCM}^{+}$probe 3 was used to measure the bed level while probes 1-2 were used to measure sediment concentration at different vertical elevations with respect to the evolving bed. By combining the concentration measurements $C(z, t)$ by probes $1-2$ with bed level measurements $z_{\text {bed }}(t)$ by probe 3 at the same cross-shore location, the sediment concentration $C\left(z^{\prime}, t\right)$ relative to the local bed level is obtained. Through averaging over multiple repeating swash events, the concentration distribution over the whole sheet flow layer can be measured. Probe $4\left(\mathrm{CCM}^{+}\right.$tank 2$)$ was also set to a bed-level tracking mode to measure $z_{\text {bed }}(t)$.

\section{Beach-face morphological evolution induced by different wave group periods}

The bed profile evolution for the present experiments was previously explored by Alsina et al. (2016); this section analyzes the bed level change in the inner surf and swash zones for conditions BE1 and BE4 in more detail. Figure 2 shows the bed profile measurements (Figure 2a) and the net sediment transport rates, $Q(x)$ (Figure $2 \mathrm{~b}$ ). The latter are mean values over the 210-min, and were calculated using the sediment conservation law (Exner equation) and a known boundary condition $(Q(x)=0)$ at the landward end of the profile. In the Exner equation, $Q(x)$ is given by:

$$
Q\left(x_{i}\right)=Q\left(x_{i-1}\right)-\int_{x_{i-1}}^{x_{i}}(1-p) \frac{\Delta z_{b}}{\Delta t} d x
$$

where $Q\left(x_{i}\right)$ is the integral volume of sediment transport $\left(\mathrm{m}^{2} / \mathrm{s}\right)$ per unit of cross tank section at position $i, \Delta z_{b}$ is the difference in bed elevation between measurement intervals $(\mathrm{m}), \Delta t$ is the time difference between measurement intervals ( $\mathrm{s}$ ) and $p$ is the sediment porosity, measured for the wave 
flume sand to be equal to 0.36 . Positive $Q(x)$ values mean landward sediment transport rates, whereas negative $Q(x)$ indicates seaward directed sediment fluxes (towards the wave paddle).

In Figure 2, the bed profiles are obtained by averaging BE1_1 and BE1_2 (BE1), and BE4_1 and BE4_2 (BE4). Both conditions produce shoreline erosion, the generation of a berm, a primary breaker bar (not shown in Figure 2 ) and a secondary bar. The latter is smaller in size and located between the breaker bar and the shoreline around $X=-6 \mathrm{~m}$ (BE1) and $X=-7.5$ $\mathrm{m}$ (BE4) (Figure 2). With increasing wave group period, the secondary bar establishes further offshore with respect to the initial shoreline. It is further interesting to see that a wider berm and secondary bar are formed for BE1 $\left(T_{g}=15.0 \mathrm{~s}\right)$ in comparison with BE4 $\left(T_{g}=27.8 \mathrm{~s}\right)$. The influence of the wave group period on the overall beach-profile evolution and on the evolution of the breaker bar was analyzed in Alsina et al. (2016). It was found that the wave group period has an important influence on the wave breaking location and on the breaker index $\gamma=H_{b r} / h$ : with increasing wave group period, the locations of wave breaking and of the breaker bar shifted offshore. Recently, Padilla and Alsina (2017) have demonstrated a clear link between the bichromatic wave group period and the location of wave breaking and bar formation, explained through second order energy transfer from the primary wave components to superharmonics and subharmonics (triad interactions) and by resultant differences in wave asymmetry. Low frequency motions are assumed to play a secondary role on the bar evolution.

As the wave group period decreases (BE1 with respect to BE4), the beachface berm and the final shoreline position are shifted landward (Figure 2). Condition BE1 produces an approximately $5 \mathrm{~m}$ wide berm (crest located around $X=7 \mathrm{~m}$ ) while BE4 produces a $2.5 \mathrm{~m}$ wide berm (around $X=3.5$ $\mathrm{m})$. The shoreline retreat (i.e. the landward shift of the shoreline) is about $2 \mathrm{~m}$ for BE4 and about $2.5 \mathrm{~m}$ for BE1. A final characteristic of the wave group period influence on the beach evolution is the beach profile variability, i.e. the rate of beach profile change, with time. Figure 2 a reveals that by the end of the experiment (210 min), the beach profile for condition BE1 is closer to a semi-equilibrium state than for BE4, hence indicating a larger beach profile variability for the latter condition. This was also observed in terms of offshore migration of the breaker bar as explained in Alsina et al. (2016).

Interestingly, the net sediment transport rates (Figure $2 \mathrm{~b}$ ) for both conditions are very similar between $X=-2.5$ and $X=1.5 \mathrm{~m}$, but magnitudes 
differ substantially at adjacent locations. The positive peak in sediment transport occurs further shoreward for condition BE1, which explains the more shoreward location of the shoreline and beach-face berm at the end of the experiment in comparison to BE4. This suggests that part of the sediment eroded at the shoreline ends at the berm, with larger shoreline erosion and berm accretion rates for condition BE1. Similarly, the negative peak in the sediment transport occurs further offshore for case BE4 than for BE1, resulting in a more seaward location of the secondary bar for condition BE4.

\section{Wave group propagation}

As stated previously, wave conditions BE1 and BE4 are characterized by a similar energy content and flux of energy but a different wave group period $\left(T_{g}=15.0 \mathrm{~s}\right.$ for BE1 and $T_{g}=27.7 \mathrm{~s}$ for BE4). The measured water surface elevation at three different cross-shore locations for wave conditions BE1_1 $(X=-67.85,-9.40$ and $0.24 \mathrm{~m})$ and BE4_2 $(X=-67.04,-8.59$ and $1.04 \mathrm{~m})$ are illustrated in Figure 3 for a short time span. The power spectral density plots corresponding to these time series are shown in Figure 4. Figures of the cross-shore distribution of amplitude for the different harmonics for BE1 and BE4 wave conditions can be found in Alsina et al. (2016). The measurements were obtained close to the wave paddle (Figure 3a,b, Figure 4 dotted lines), at the breaking location (Figure 3c,d, Figure 4 dashed lines) and at the lower swash zone where also $\mathrm{CCM}^{+}$tank 1 is located (Figure 3e,f, Figure 4 solid lines). Each panel in Figure 3 shows the ensemble of eight experimental runs (time series of 30 min.) and the ensemble-mean. A relatively small water surface variability is found with an average standard deviation below $10 \%$ of the measured wave height at each location. This variability is partly explained by the bed level variability between tests.

The different wave modulation between wave conditions BE1 and BE4 is evident from Figure 3a,b: the same wave energy content is distributed over four short waves for condition BE1 and over eight short waves for BE4 that have the same mean short wave period (mean primary period $\left.T_{p}=1 /\left(f_{1}+f_{2}\right)\right)$. Just after generation the two primary wave frequencies $\left(f_{1}\right.$ and $\left.f_{2}\right)$ dominate the wave energy with an important contribution from the wave group frequency, $f_{g}$ (Figure 4 ). During wave propagation, energy transfer from primary components to sub-harmonics and super-harmonics occurs due to non-linear triad interactions. This energy transfer occurs at the expenses of the primary frequencies $\left(f_{1}\right.$ and $\left.f_{2}\right)$ which decrease in energy 
during wave shoaling (Baldock et al., 2000; Alsina et al., 2016; Padilla and Alsina, 2017). The growth of superharmonics during wave shoaling causes the high frequency waves to become more asymmetric and unstable, eventually leading to wave breaking (Elgar and Guza, 1985; Padilla and Alsina, 2017). Because of energy dissipation of the short wave frequencies due to breaking, the wave group frequency component becomes progressively more important after breaking (Figure 4). When the wave groups arrive at the swash zone, the energy at $f_{g}$ dominates over $f_{1}$ and $f_{2}$. Nevertheless, the wave group structure still comprises individual waves that are evident in the time series (Figure 3e,f). For wave conditions BE1, the wave energy at $f_{R}=1 / T_{R}(0.005 \mathrm{~Hz})$ is negligible compared to other components (Figure 4a).

Close to the shoreline, when the wave groups reach shallow water, the celerity of the individual waves forming the groups depends on the water depth. Therefore, individual waves (bores) travelling at the crest of the long wave move faster than waves travelling at the trough (Tissier et al., 2015; Padilla and Alsina, 2017), causing wave "merging" or "focusing" at the long wave crest. This wave focusing is observed in Figure 3 for wave condition BE1, where wave groups consist of $4-5$ waves after generation, but they have merged into 2-3 waves at the lower swash zone. For condition BE4 by contrast, all individual waves at generation are still present at the lower swash zone. This difference is explained by a larger amplitude of the low frequency wave at the inner surf zone for BE1 (Alsina et al., 2016), leading to stronger bore focusing.

\section{Swash zone hydrodynamics, suspended sediment dynamics and time-dependent bed evolution}

In this section, the swash zone hydrodynamics will be presented and connected to the measured suspended sediment dynamics and time-dependent bed elevation measured with the $\mathrm{CCM}^{+}$. We refer to suspended sediment transport as the sediment measured using the OBS sensors which are located approximately $3-5 \mathrm{~cm}$ above the bed. We refer to bed-load/sheet flow sediment transport as the sediment concentration measured in the thin (around $1 \mathrm{~cm}$ thickness) sheet-flow layer using the $\mathrm{CCM}^{+}$sensors.

The time-dependent shoreline motion has been computed from the AWG measurements, by spatially interpolating the water surface level at every time step and computing the intersection of the water surface with the beach pro- 
file, as explained in more detail in Alsina et al. (2012). The average separation between AWG sensors at the beach face is $0.89 \mathrm{~m}$ and therefore the horizontal accuracy is theoretically around $\pm 0.44 \mathrm{~m}$. However, exact values depend on the instantaneous water surface shape in the swash zone. The computed shoreline cross-shore location was compared with visual observations of maximum runup and minimum rundown. The runup was visually measured to reach maximum locations of $X=9.2,8.6,4.9$ and $4.8 \mathrm{~m}$ whereas the computed maximum runup from AWG sensors was $X=9.25,9.00,3.92$ and 4.62 m for conditions BE1_1, BE1_2, BE4_1, and BE4_2, respectively. Similarly, the minimum rundown location was visually estimated to reach $X=-0.2$, $-1.1,0.9,0.3 \mathrm{~m}$ on average and computed from AWG measurements to be $X=-0.80,-0.83,0.40$ and $0.90 \mathrm{~m}$ (wave conditions BE1_1, BE1_2, BE4_1, and BE4_2, respectively). The acoustic sensors seem to provide a good description of the shoreline evolution during the uprush and maximum runup but it tends to under-predict the rundown obtained from visual observations, likely due to the presence of a thin swash lens during the last stages of the backwash.

\subsection{Shortest wave group period, BE1}

\subsubsection{Swash zone hydrodynamics}

Contour plots of ensemble-averaged water surface elevation in the swash zone and the instantaneous shoreline motion are shown in Figure 5 for wave condition BE1_1. Ensemble averaging is performed here over the repeat frequency $T_{R}$, i.e. 13 wave group periods. Most waves arrive at the shoreline as broken waves. These broken waves collapse at the shoreline and then climb the beach-face while interacting with the preceding swash events and with the next arriving waves. It is observed that for conditions BE1, the shoreline moves up and down almost as a single swash event at the temporal scale of the wave group period, although individual waves and wave-swash interactions are still evident.

The measured water surface elevation and velocity at different crossshore locations are illustrated for BE1_1 in Figure 6a,b. The water surface elevation (panel a) shows that, although the relative phase of the individual waves is different for all 13 swash events, the events repeat approximately after every second wave group. Wave groups 2, 4, 6, 9, 11 and 13 are highly similar, each group composed of three waves per group with a central wave of larger wave height. Henceforth we will group those events as type A swash events. Similarly, wave groups 1, 3, 5, 7 and 12 also show high similarity and 
henceforth are termed type B swash events. Type B swash events consist of a small wave at the beginning of the wave group, as measured at $X=-0.47$ $\mathrm{m}$, and two central larger waves with slightly varying phase and elevation for each group. The grouping of swash events as type A and B is similar to the grouping done by van der Zanden et al. (2015) and it is motivated not only by the measured hydrodynamics but also by the sediment transport processes, as will be explained later. The hydrodynamic variability between wave groups for both types of events is discussed extensively by van der Zanden et al. (2015).

In order to study processes at an intra-swash time scale, the swash events of type $\mathrm{A}(2,4,6,9,11$ and 13) and of type $\mathrm{B}(1,3,5,7$ and 12) were ensemble-averaged. The ensemble-averaged water surface elevation contours, shoreline position and horizontal velocity vectors are shown in Figure $7 \mathrm{a}, \mathrm{b}$ while the measured water surface elevation at four locations around the inner surf and swash zone limit is shown in Figure $7 \mathrm{c}, \mathrm{d}$. The incoming waves (bores) at $X=-0.47 \mathrm{~m}$ are identified with arrows. The time-dependent shoreline and swash zone behaviour is slightly different for type A and B. The type A swash is characterized by a maximum runup at $t / T_{g} \approx 0.38$ (Fig. 7a) induced by the first arriving bore (Fig. 7c first arrow) and a secondary runup at around $t / T_{g}=0.7$ induced by the second arriving bore after interacting with the preceding backwash. On the other hand the type B swash event produces a maximum runup at around $t / T_{g}=0.47$ induced by the combined action of two incoming bores (see Fig. $7 \mathrm{~b}$ and $\mathrm{d}$ ) while the third arriving bore does not produce a secondary runup.

Time series of ensemble-averaged water surface elevation and velocity at different cross-shore locations for swash type A and B are shown in Figures $8 \mathrm{a}, \mathrm{b}$ (water surface elevation) and c,d (velocity). In the swash events of type $\mathrm{A}$, an initial wave crest arriving at $X=-0.47 \mathrm{~m}$ at $t / T_{g} \approx 0.12$ generates a first large uprush that produces high onshore velocity. A second, larger wave crest (central wave) arrives at roughly $t / T_{g}=0.4$, and interacts with the preceding backwash. The momentum associated to the receding backwash is lower than the momentum of the incident wave and therefore the second wave continues climbing the beachface. Because the backwash momentum is lower than the momentum of the next arriving wave, this type of interaction is called a weak wave-backwash interaction (Hughes and Moseley, 2007; Caceres and Alsina, 2012). As a result, the second wave interrupts the negative backwash velocity and produces a positive velocity peak of short duration at lower swash cross-shore locations $(X<1 \mathrm{~m}$ in 
Figure 8c), indicating onshore wave propagation, and it causes a secondary runup. This second runup is smaller than the initial runup, despite the higher incident wave height. A third wave, with smaller wave height, arrives during the late stage of the wave group induced backwash and, in this case, the greater momentum of the backwash displaces the third wave seaward $\left(t / T_{g} \approx 0.85\right)$, as seen in the velocity signal (Fig. 8c) where the velocity remains negative at $X=-0.47 \mathrm{~m}$ despite the arriving bore.

In the swash events of type B (Fig. 8b,d), the first arriving wave is relatively small (indicated with an arrow in Fig. $8 \mathrm{~b}$ at $X=-0.47 \mathrm{~m}$ at $\left.t / T_{g} \approx 0.08\right)$, and it is captured during the uprush by a second and larger wave $\left(t / T_{g} \approx 0.2\right.$ at $\left.X=-0.47 \mathrm{~m}\right)$; a process termed wave-capture (Caceres and Alsina, 2012; Alsina et al., 2012). The merged bores propagate further shoreward, inducing a maximum runup at $t / T_{g}=0.47$. The backwash generated by these merged bores is characterized by significantly higher offshore-directed velocity than for type A (c.f. Fig. 8c and d). A third wave arrives at $X=-0.47 \mathrm{~m}$ during the preceding backwash $\left(t / T_{g} \approx 0.6\right)$. In this case, the momentum of the backwash exceeds the momentum of the third arriving wave, causing a stationary bore that is displaced seaward by the long backwash (i.e. strong wave-backwash interaction). This is evident from the water surface signal at $X=2.27 \mathrm{~m}$ at around $t / T_{g}=0.6$ (third arrow in Fig. 8b), as the third wave does not arrive at that location, and from the velocity signal (Fig. 8d), as the third wave does not produce a positive velocity signal at any cross-shore location.

\subsubsection{Suspended sediment dynamics}

Suspended sediment fluxes at given locations were calculated as $u C$, where $u$ is the horizontal velocity (in $\mathrm{m} / \mathrm{s}$ ) and $C$ is the volumetric suspended sediment concentration (in $\mathrm{m}^{3} / \mathrm{m}^{3}$ ). Ensemble-averaged time series of $C$ and $u C$ for type $\mathrm{A}$ and $\mathrm{B}$ swash events are illustrated in Figure $8 \mathrm{e}-\mathrm{h}$. Bed level variations within a 30-minute hydrodynamics run were observed with a variability of around $6-7 \mathrm{~cm}$ at the beginning of each experiment (first hydrodynamic runs) and of around $1-3 \mathrm{~cm}$ at the end of each experiment (last hydrodynamic runs). Therefore, ensemble-averaging is performed over the last 6 hydrodynamic runs where the bed is more stable and the variations in relative sensor elevation are smaller. The suspended sediment concentration shows, for both type of swash events, two main peaks of sediment concentration per wave group induced swash; each peak corresponding with maximum and minimum velocity values during the uprush and back- 
wash. This situation resembles suspended sediment dynamics measured in the swash region under short waves (Caceres and Alsina, 2016). In both type of swash events (A and B) the main uprush induces large peaks of sediment concentration at different cross-shore locations (Fig. 8e and f). The uprush velocity magnitudes decrease slightly with cross-shore location during the initial runup due to deceleration of the swash bore. However, the suspended sediment concentration increases with increasing cross-shore distance $X$. This is attributed to a gradual increase in suspended load under the bore, which propagates across the swash zone whilst entraining sediment and transporting it shoreward. This indicates that the concentration is not only controlled locally by the velocity (local vertical pick-up) but also grows due to a net influx along the bed (advection effect). This process is more evident for type A than type B events, due to the larger wave height and flow velocity at the arrival of the first incident bore.

The uprush of wave type B, characterized by a smaller first incident wave followed by a second wave arriving shortly after, is less effective in mobilizing sediment. For a bore collapsing on a dry bed (first wave in type A), the fluid parcels at the bore front converge at the bed, leading to a large shear stress (Baldock et al., 2014). However, when a bore propagates over a previous runup (type B), the flow does not converge directly at the bed and the bed friction is expected to be smaller and sediment mobilization is reduced. Moreover, turbulence under a collapsing bore might be higher and acts more directly on the sediment bed than under a wave capture event. Other authors have suggested a positive influence of horizontal pressure gradients, including the inertial contribution, on sediment mobilization during the uprush (Lanckriet and Puleo, 2015).

During the main wave group induced backwash, the different wave-backwash interactions that occur for swash events A and B clearly affect the sediment dynamics. For the swash event of type A, the sediment concentration shows a local maximum during the second wave backwash (Fig. 8e). This sediment concentration peak appears first at $X=2.27 \mathrm{~m}$ (at around $t / T_{g}=0.55$ ) and slightly later at locations lower in the swash zone (at $t / T_{g} \approx 0.6$ at $X=-0.47 \mathrm{~m}$ ), hence suggesting offshore advection of suspended sediment during the backwash. However, the seaward sediment advection is less clear since the velocity patterns are not so similar due to the presence of interactions. During the main backwash of swash event type B (Fig. 8f), a local maximum in concentration occurs at $X=2.27 \mathrm{~m}\left(t / T_{g}=0.6\right)$, which may relate to local pickup given the high offshore-directed flow velocity. The 
concentration time series between $X=-0.47$ and $1.36 \mathrm{~m}$ do not show such evident peaks, which indicates that the horizontal influx of suspended sediment during the backwash is lower at these locations. This lower influx likely relates to the third swash bore and the associated strong wave-backwash interaction at $X=-0.5$ to $1.5 \mathrm{~m}$ which reduces the momentum of the backwash and, consequently, forces the settling of suspended sand particles.

For swash events of type A the onshore sediment fluxes are of larger magnitude but they occur over a shorter time, compared to the fluxes during the backwash which are smaller in magnitude but longer in duration (Fig. $8 \mathrm{~g})$. For these events, the second incident wave which induces a weak wavebackwash interaction (around $t / T_{g}=0.4$ ) produces positive sediment fluxes at $X=-0.47 \mathrm{~m}$, but it does not interrupt the offshore-directed sand fluxes at locations further landward. Between $t / T_{g}=0.50$ and 0.85 , sand fluxes for swash events $\mathrm{A}$ are quasi-steady and of same magnitude at all locations, regardless of the arrival of a third incident wave at $t / T_{g} \approx 0.75$.

For swash events of type $\mathrm{B}$, the two bores merging during the uprush produce onshore sand fluxes that are of lower magnitude but of longer duration relative to the fluxes for the type A events (Fig. 8h). The backwash leads to local fluid acceleration (negative) and offshore-directed sand fluxes $\left(t / T_{g}\right.$ $=0.4$ to 0.65 ) that are of highest magnitude at $X=2.27 \mathrm{~m}$ and that decay in offshore direction due to the strong wave-backwash interaction, associated with the third incident wave, that reduces the backwash velocity and sediment flux magnitudes.

\subsubsection{Time-dependent bed level}

The time-dependent bed level measured directly by the $\mathrm{CCM}^{+}$sensors 3 and 4 in bed-level tracking mode is composed of a general trend, erosive or accretive depending on the $\mathrm{CCM}^{+}$sensor cross-shore location within the swash zone (accretion at the berm and erosion close to the rundown location), and bed level oscillations at different time-scales which relate to the hydrodynamic forcing, as shown in Alsina et al. (2014) and van der Zanden et al. (2015) for condition BE1_2. The general trend follows a rapid bed evolution at the beginning of experiments and, after a while, it tends towards a quasi-equilibrium situation.

The time-dependent bed evolution is therefore decomposed into an overall trend (erosive or accretive) and a wave-group induced bed level. The wavegroup component is obtained by ensemble averaging the de-trended signal (by high pass filtering the $\mathrm{CCM}^{+}$signal) at the time-scale $T_{R}$ at which 
wave groups repeat exactly $\left(T_{R}=T_{g}\right.$ for BE4 and $T_{R}=13 T_{g}$ for BE1). For condition BE1_1, the ensemble-averaged bed level values at cross-shore locations $X=0.24 \mathrm{~m}$ and $X=2.27 \mathrm{~m}$ are shown in Figure $6 \mathrm{~d}$,e (at $T_{R}$ time scale) and in Figure 8i,j (at the $T_{g}$ time scale for type A and B events). As reported by van der Zanden et al. (2015), these direct bed level measurements with $\mathrm{CCM}^{+}$probe 3 suffer from time lags of about $1 \mathrm{~s}$ when compared to the more accurate measurement obtained from the vertical concentration distribution in the sheet flow layer. Both bed level measurement approaches will be compared in Section 7.3.

The time-dependent bed level at the wave group time scale $\left(T_{g}\right)$ shows cycles of erosion and accretion (Fig. 8i, j). For the swash events of type A, the bed level at $X=0.24 \mathrm{~m}\left(\mathrm{CCM}^{+}\right.$tank 1$)$ erodes during the uprush, indicating that more sediment is transported landward than enters from the inner surf zone (Fig 8i). At $X=2.27 \mathrm{~m}$ (tank 2$)$ the bed level drops a few $\mathrm{mm}$ as the first wave arrives $\left(t / T_{g}=0.15\right)$, but it recovers during the remainder of the uprush (after $t / T_{g}=0.25$ ) due to a positive advective influx of sediment coming from the lower swash locations. In contrast, during the backwash, the bed level at both locations shows accretion induced by the arrival of advected sediment from locations further landward (i.e. from $X>2.27 \mathrm{~m}$ ). For swash events of type $\mathrm{B}$, the bed elevation at $X=0.24 \mathrm{~m}$ shows erosion during the initial uprush, a stable bed period during $0.25 \leq t / T_{g} \leq 0.7$ and accretion during the late stages of the backwash. This intra-swash bed level behaviour for event B is similar to the fluctuations for event A, but the amplitude is substantially smaller. At $X=2.27 \mathrm{~m}$, the bed level shows a progressive erosion that starts during the uprush $\left(t / T_{g}=0.15\right)$ and continues during the backwash (until $t / T_{g}=0.70$ ). This suggests a net outflux of sediment from this location to higher swash regions during the uprush and a net sediment outflux towards lower swash elevations during the backwash. Note that the bed level behaviour at $X=2.27 \mathrm{~m}$ is nearly opposite for the events of type $\mathrm{A}$ and $\mathrm{B}$.

Overall, type A swash events produce a net erosion of about $1 \mathrm{~mm}$ at $X=0.24 \mathrm{~m}$ as the bed level gain during the backwash is smaller than the erosion produced during the uprush, indicating a net transport of sediment from this location to the inner surf zone and the berm. At $X=2.27 \mathrm{~m}$, on the contrary, net accretion of about $3 \mathrm{~mm}$ occurs for swash events of type A. The net bed level change for type $\mathrm{B}$ events is remarkably different, with a net accretion of about $1 \mathrm{~mm}$ at $X=0.24 \mathrm{~m}$ and net erosion of about $3 \mathrm{~mm}$ at $X=2.27 \mathrm{~m}$. 
For condition BE1, the phasing between the individual waves changes progressively during the wave sequence at the repetition period, $T_{R}$, leading to different types of wave-swash interactions within a $T_{R}$ cycle. These types of interactions are reflected in the water surface elevation, velocity, suspended sediment concentration and bed elevation. The resultant bed evolution obtained from the conductivity probes at the repetition time scale shows cycles of erosion and accretion, driving a bed level fluctuation at $T_{R}$ with amplitudes of 1 and $3 \mathrm{~mm}$ for $X=-0.47$ and $X=2.27 \mathrm{~m}$ respectively (Fig. 6d,e). The water surface motion at $T_{R}$ is considered negligible with a measured amplitude of $2 \mathrm{~mm}$ at $X=-0.47 \mathrm{~m}$ which is one order or magnitude smaller than the amplitude of the water surface motion at $T_{g}$. This long wave is generated by variations in the short wave breakpoint occurring at $T_{R}$. Previous authors have also measured water surface level fluctuations at $T_{R}$ (Baldock et al., 2000; Moura and Baldock, 2018). As the wave motion at $T_{R}$ is very small, it is not likely that the long-wave water surface and velocity modulation at $T_{R}$ directly drives the bed level fluctuation at the repeat frequency. Instead, the transport processes behind the measured bed evolution at $T_{R}$ are related to changes in the phasing of the individual waves and the type and strength of wave-swash interactions within the $T_{R}$ cycle (Alsina et al., 2014; van der Zanden et al., 2015).

\subsection{Longest wave group period, BE4}

\subsubsection{Swash zone hydrodynamics}

A contour plot of ensemble-averaged water surface elevation in the swash zone and the time-dependent shoreline position is shown in Figure 9 for wave condition BE4_2. Ensemble-averaging is performed here over one wave group period $\left(T_{g}=27.7 \mathrm{~s}\right)$. The shoreline oscillation is influenced by the wave group period but the individual waves are still evident and promote individual swash events. This is especially clear at the end of the wave group where a succession of individual waves controls the shoreline oscillation (Figure 9 at $\left.t / T_{g} \geq 0.6\right)$. Visual observations and the computed shoreline location show that the maximum runup cross-shore location is substantially smaller for BE4 than for BE1, despite the same wave energy content upon wave generation.

The ensemble-averaged water surface elevation and horizontal velocity at different cross-shore locations for wave condition BE4_2 is shown in Figure 10a, b. Different cross-shore locations are illustrated, covering a cross-shore region of around 0.80 times the maximum runup. The height of the individual waves decays with cross-shore distance. The horizontal velocity shows 
the influence of the short waves, with alternating positive and negative values during the uprush and backwash associated with each incident wave, and the presence of a long-wave induced velocity component that is approximately in antiphase with the long-wave induced water surface elevation (i.e. negative long wave velocity at the long wave crest). Compared with BE1, the horizontal swash velocities for BE4 are of smaller magnitude and the uprush and backwash cycles are of shorter duration.

\subsubsection{Suspended sediment dynamics and bed evolution}

The ensemble-averaged suspended sediment concentration, suspended sediment flux and bed evolution (measured with $\mathrm{CCM}^{+}$probe 3) are illustrated in Figures 10c-e. The measured sediment concentrations at locations in the upper swash region $(X>1.5 \mathrm{~m})$ show sediment concentration peaks under the largest arriving bores. However, the cross-shore locations closer to the rundown $(X<1.5 \mathrm{~m})$ show sediment concentration events only at the beginning $\left(t / T_{g} \approx 0.1\right)$ and in the middle $\left(t / T_{g} \approx 0.4-0.6\right)$ of the wave group, when individual waves arrive at low water levels. This influence of the long wave water level modulation on sediment suspension in the inner surf-swash zone limit has been observed previously by Alsina et al. (2009) and Alsina and Caceres (2011); the former study reported a minimum bore height to water depth ratio of approximately 1:1 to induce sediment suspension.

There is no clear evidence of suspended sediment advection for condition BE4_2, likely because of the smaller velocity magnitudes, the reduced runup and short duration of individual swash events. In contrast to wave condition BE1 where the suspended sediment fluxes fluctuate predominantly at the wave group time scale, the computed sediment fluxes for BE4 show a long wave pattern but are largely controlled by the individual waves. The sediment fluxes are alternately onshore-offshore directed during individual swash events. At $X>1.5 \mathrm{~m}$, the highest flux magnitudes are observed under the largest bores that occur at the long wave crest, but at $X \leq 1 \mathrm{~m}$ largest sediment fluxes are associated with large bores on low water levels. In general the suspended sediment fluxes are significantly larger for wave condition $\mathrm{BE} 1$ in comparison to BE4, due to the combination of both higher horizontal velocities and suspended sediment concentration for BE1.

The measured bed evolution $X=1.05 \mathrm{~m}$ for BE4_2 shows a significantly smaller variability than BE1, with bed level changes of around $1 \mathrm{~mm}$. The bed evolution shows a larger influence of the individual waves with cycles of erosion and accretion predominantly during the individual uprush (erosion) 
and backwash (accretion) events. It also shows a long wave modulation, with erosion occurring in presence of relatively large waves during low water levels $\left(0.3<t / T_{g}<0.8\right)$ and accretion during the smaller waves.

\section{Sheet flow dynamics}

The sediment dynamics in the sheet flow layer are investigated in this section. The capabilities of the $\mathrm{CCM}^{+}$tank to measure sediment concentration and bed evolution have been explained by van der Zanden et al. (2015). Here their approach is followed closely.

As demonstrated in van der Zanden et al. (2015), the $\mathrm{CCM}^{+}$probes in fast tracking mode can accurately measure the bed level changes at temporal scales of the wave group period and longer. Bed elevation changes with a shorter temporal scale (intra-group, intra-wave) can be obtained from the vertical distribution of ensemble-averaged concentrations within the sheet flow layer. By generating repeatable wave conditions and by ensemble-averaging the data, the concentration distribution $C\left(z^{\prime}, t / T\right)$ over the whole sheet flow layer is obtained. The time-dependent bed level within a wave group is then quantified as the sheet flow pivot point, which is the middle of the sheet flow layer and which corresponds to the elevation where the volumetric concentration $C / C_{b}=0.44 \mathrm{~m}^{3} / \mathrm{m}^{3}$ (O'Donoghue and Wright, 2004), where $C_{b}$ is the concentration in the bed $\left(=0.64 \mathrm{~m}^{3} / \mathrm{m}^{3}\right.$ in this experiment). Because of the discrete number of measurements, the pivot point is quantified by fitting the empirical model of O'Donoghue and Wright (2004) to the obtained measurements. The O'Donoghue and Wright (2004) model reads:

$$
C\left(z^{\prime}, t\right)=C_{b} \frac{\beta(t)^{\alpha}}{\beta(t)^{\alpha}+\left[z^{\prime}+z_{e}\right]^{\alpha}}
$$

where $C\left(z^{\prime}, t\right)$ is the volumetric concentration $\left(\mathrm{m}^{3} / \mathrm{m}^{3}\right)$ at height $z^{\prime}(\mathrm{mm})$ relative to the original bed at instant $t ; \beta(t)$ and $\alpha$ are shape factors; and $z_{e}(t)$ is the so-called erosion depth of the sheet flow layer which marks the bottom of the sheet flow layer. For the present data, the least-square fit of Eq. (3) through the data is obtained using $\beta$ and $z_{e}$ as fitting parameters while a fixed value of $\alpha=1.5$ (established for medium sand by O'Donoghue and Wright (2004)) is used. The agreement of Eq. (3) to the data is good with an average coefficient of determination of $r=0.86$ for wave condition BE1_1 and $r=0.80$ for BE4_2 (plots of fit-to-data can be found in van der Zanden et al. (2015) for BE1_2). Based on the fitted curves, the time-dependent 
pivot point and the sheet flow layer thickness $\left(\delta_{s}\right)$ are quantified. The latter is defined as the distance between the bottom of the sheet flow layer and the level where $C=0.08 \mathrm{~m}^{3} / \mathrm{m}^{3}$ (Dohmen-Janssen and Hanes, 2002; O'Donoghue and Wright, 2004).

The measured sediment concentration time series $C\left(z^{\prime}, t\right)$ are grouped into six concentration bins based on wave-group-averaged concentration, ranging from $C=0$ to $0.6 \mathrm{~m}^{3} / \mathrm{m}^{3}$ with steps of $0.1 \mathrm{~m}^{3} / \mathrm{m}^{3}$, and are then phaseaveraged. For each concentration class, the mean vertical elevation $z^{\prime}$ with respect to the wave-group-averaged bed level is obtained (variability +/2.5 and $3.4 \mathrm{~mm}$ for BE1_1 and BE4_2 respectively). The phase-averaged concentrations are calculated over a minimum of 60 swash events.

Finally, particle velocities in the sheet flow layer are obtained following the methodology of McLean et al. (2001). This methodology assumes that when a cloud of sediment particles with a concentration $C$ passes both $\mathrm{CCM}^{+}$ probes 1 and 2, the sediment particle velocity can be obtained from the time lag in $C$ between both probes. The time lag is obtained from cross-correlating the high-pass filtered ( $1 \mathrm{~Hz}$ cutoff) concentration measurements of the two sensors. This is done for short-duration $\left(\Delta t=T_{g} / 100\right)$ intervals of the time series; the cross-correlation output is then phase- and bin-averaged to obtain the particle velocity $u_{p}\left(z^{\prime}, t / T_{g}\right)$ for a concentration bin class at a mean vertical elevation $z^{\prime}$. The particle velocities are calculated over a minimum of 90 swash events per concentration bin.

\subsection{Wave condition with the smallest wave group period, BE1}

The sheet flow dynamics for wave condition BE1_1 measured at $X=0.24$ $m$ were ensemble-averaged over wave types $A$ and $B$, the results are shown in Figure 11 (left plots correspond to swash type A and right plots to swash type B). Sediment concentrations in the sheet flow layer (Fig. 11e-f) are at all vertical elevations high around $t / T_{g}=0$ and decrease during the first wave uprush $\left(t / T_{g}=0.1\right)$. Sediment distributions do not follow the characteristic mirroring concentration patterns in the pick-up and upper sheet flow layers, as shown for non-breaking waves and indicative of a vertical exchange of sediment (Dohmen-Janssen and Hanes, 2002, 2005; O'Donoghue and Wright, 2004; Ribberink et al., 2008; Schretlen, 2012). The fact that concentrations decrease at all elevations indicates that sediment is not purely re-distributed vertically over the sheet flow layer (as happens for oscillatory sheet flows) but that instead, a major sediment fraction is horizontally advected landward. During the end of the backwash stages of both types of swash events $\left(t / T_{g}=\right.$ 
0.7 to 1.0 ), on the contrary, sediment concentrations increase at all elevations, hence indicating the arrival of sediment that is advected seaward from the upper to the lower swash zone. The patterns in Fig. 11e-f are generally similar for swash type A and B.

The timing of peaks in suspended sediment concentration during the uprush (Fig. 11g-h) are consistent with concentration variations in the sheetflow layer (and rapid erosion), with a slight time lag of about $0.1 T_{g}$. This time lag may be explained by phase leads of velocity in the sheet flow layer or it may indicate the time that is required for sediment to travel from the bedload layer to the vertical elevations of the OBS sensors.

The particle velocities (Fig. 11c-d) reveal that horizontal transport in the sheet flow layer occurs primarily during the early uprush and late backwash stages. During these stages, the horizontal fluxes (Fig. 11i-j) in the sheet-flow layer (dots) are more than an order of magnitude higher than the suspended sediment fluxes (lines; see also Fig. 8g-h). However, during flow reversal or during events of wave-swash interactions, suspended sediment fluxes can be higher. Moreover, because suspended sediment transport extends over the full swash column, $\mathcal{O}(0.1 \mathrm{~m})$, while the sheet flow layer thickness is of $\mathcal{O}(0.01 \mathrm{~m})$, the depth-integrated suspended transport might be of similar or higher magnitude as the sheet flow transport (Puleo et al., 2016).

The temporal distribution of the pivot point (Fig. 11k-l) reaffirms the direct bed level measurements by $\mathrm{CCM}^{+}$probe 3 , indicating bed erosion during the uprush as sediment is moved landward from $X=0.27 \mathrm{~m}\left(\mathrm{CCM}^{+}\right.$ tank 1) to locations higher on the beach face, but bed accretion during the backwash as sediment is moved from locations up on the beach face to $X=$ $0.27 \mathrm{~m}$. A closer look to Figure $11 \mathrm{k}-1$ shows that type A swash events produce a larger bed reduction during the first $0.3 T_{g}$ than swash events of type B. The reason is the impact of a higher first wave on the dry bed, with a higher onshore velocity leading to more erosion and landward sediment advection at the beginning of the uprush for wave type A (as also discussed in Section 5.1.2).

The thickness of the sheet flow layer $\delta_{s}$ for wave condition BE1_1 is shown in Figure 12e and $\mathrm{f}$ for swash type $\mathrm{A}$ and $\mathrm{B}$ respectively. As also addressed by van der Zanden et al. (2015), $\delta_{s}$ for the present swash measurements is relatively high compared to measurements under non-breaking waves with similar grain size and local velocity magnitudes. This can be attributed to additional hydrodynamic forcing parameters that mobilize sediment in the sheet flow layer, such as bore turbulence and horizontal pressue gradients (e.g. 
Lanckriet and Puleo (2015)), and to effects of horizontal sediment advection (van der Zanden et al., 2015).

The results show that the sheet flow layer is thickest during late backwash stages where negative velocity is more constant and it decays during the uprush. It has been argued by van der Zanden et al. (2015) that the thick sheet flow layers during the backwash stages are probably driven by a influx of sediment coming from the higher swash regions. The sheet flow layer during the backwash is slightly more developed for swash event of type B than for event A despite similar free-stream velocity magnitudes. This higher sheet flow layer thickness for event B relates probably to the longer-duration backwash for this event, leading to a more developed sheet flow layer. During the uprush, a more abrupt decay is observed during the initial uprush of events $\mathrm{A}$. This relates to the higher onshore velocity and large erosion during the A event uprush.

\subsection{Wave condition with largest wave group period, BE4}

The sheet flow dynamics in the swash zone for wave condition BE4_2 are illustrated in Figure 13. Wave condition BE4_1 (not shown) displayed very similar dynamics but at a different $X$ location $(X=0.45 \mathrm{~m})$. Because of the lower velocity magnitudes and shorter durations of individual uprush/backwash cycles, the sheet flow layer is thinner than for wave condition BE1_1 (Figure 13f). For these thin sheet flow layers, the particle velocity measurements were not sufficiently accurate because the cross-correlations between $\mathrm{CCM}^{+}$probes 1-2 were too low. This however does not affect the ensemble averaged concentration.

The sediment concentration time series for condition BE4_2 (Figure 13c) show evidence of sediment pick up at the bottom of the sheet flow layer and resuspension at the top of the sheet flow layer (at $t / T_{g} \approx 0.42,0.60,0.74$ and 0.87 ). The timing of these suspension events are coincident with erosion in the measured bed elevation, and it reveals a consistent growth of the sheet flow layer during each backwash event for $t / T_{g}>0.3$ and resuspension at the end of the backwash stage and transition to the next uprush. The arrival of the incident bores interrupts this growth and reduces the sheet flow layer. These sheet flow layer dynamics are also illustrated in the time distribution of the sheet flow layer thickness (Figure 13f), showing cycles of sheet flow layer development during backwash events and decay during uprush events, especially for $t / T_{g}>0.3$. On the other hand, the uprush and backwash events associated with waves arriving at relatively high water level 
(at $0.1<t / T_{g}<0.3$ ) generate low velocities leading to low bed-shear stress and therefore thin sheet flow layers.

The suspended sediment concentration measured with OBSs (Figure 13d) shows concentration peak events that occur at the late backwash/early uprush stages associated with the incident bores arriving at low water elevation. Most of the suspension concentration peaks (for $t / T_{g}>0.4$ ) coincide well in time with the sheet flow concentration peaks, suggesting again quick vertical mixing ('local control'). The sediment concentration contour plot distribution (Fig. 13e) also shows the bed erosion events as a result of the pick up events during the arrival of individual bores at low water levels. The amplitude of the time-dependent bed level change at the wave group time scale is much smaller for condition BE4 than for BE1 $(\approx 1 \mathrm{~mm}$ for BE4 and $\approx 4$ $\mathrm{mm}$ for BE1).

\section{Summary and discussion}

The interaction of wave groups on a sloping beach results in complex swash zone hydrodynamics determined by interactions between arriving turbulent bores, low frequency water surface motions and swash flows generated by the collapse of preceding bores on the beach. These hydrodynamics conditions are powerful agents for sediment motion and beachface evolution. In the present large-scale laboratory conditions, controlled wave groups were generated with constant wave energy but with varying wave group period to isolate the effect of specific wave group influence on swash zone sediment transport. The present section addresses how the different wave grouping affects the swash zone hydrodynamics (Section 7.1), cross-shore sediment exchange (Section 7.2) and sheet flow layer dynamics (Section 7.3).

\subsection{Wave-group-induced swash events}

Because of the relatively steep beach slope (1:15) used in these experiments, the wave group induced swash events for both conditions are characterized by the presence of individual bores and low frequency swash motions. Despite having the same incident wave energy flux, the two presented wave conditions differ notably in terms of amplitude of the low-frequency swash motion and in terms of the strength of incident bores.

For the given wave and beach slope conditions, the shortest tested wave group (BE1, $T_{g}=15.0 \mathrm{~s}$ ) resulted in a larger low frequency wave amplitude close to the shoreline than the longer wave groups $\left(\mathrm{BE} 4, T_{g}=27.7 \mathrm{~s}\right)$ as 
reported by Alsina et al. (2016). As described in Section 4, the more pronounced bore focusing and larger long wave amplitude for BE1 results in a larger swash zone excursion and causes the time-dependent shoreline dynamics to behave almost as a single wave group-induced runup and rundown, although the arrival of three individual bores is evident in the water surface signal and leads to distinct wave-swash interactions. In contrast, the swash zone induced by wave condition BE4 is characterized by the presence of multiple bores and the shoreline moving up and down at the time scale of the individual waves. As a result, the overall beach profile evolution shows a larger active swash region for BE1, in comparison with condition BE4. Several works have studied the influence of wave groups and associated low frequency motions on wave runup (Brocchini and Gentile, 2001; Guedes et al., 2013; Sheremet et al., 2014; Guza and Feddersen, 2012) and low frequency motions are typically included in empirical run-up formulations (Stockdon et al., 2006). Guza and Feddersen (2012) showed numerically that increasing the spectral bandwidth of the incident sea states results in a runup reduction. Consistent with the latter study, condition BE4 is characterized by a higher frequency difference or bandwidth $\left(\Delta f=f_{1}-f_{2}\right)$ and a reduced run-up relative to BE1.

\subsection{Influence of wave-swash interaction on sediment suspension and advec- tion}

Because of the variation of the short wave phase at the repetition period $T_{R}=13 T_{g}$ for condition BE1, the influence of the wave sequence within the group could be studied. The time-dependent bed elevation measured with conductivity probes is observed to fluctuate both at temporal scales of the group period $\left(T_{g}\right)$ and repetition period $\left(T_{R}\right)$. The amplitude of the bed evolution at $T_{R}$ is equal or larger than the amplitude of the water surface at $T_{R}$. The bed level fluctuations at $T_{R}$ are therefore attributed to changes in the wave sequencing and wave-swash interactions occurring at a $T_{R}$ cycle.

Both single and interacting uprush and backwash events occurs during a $T_{R}$ cycle for BE1. This includes single uprush events, a bore overrunning a previous uprush ("wave capture") and "weak" and "strong" wave-backwash interactions. Based on the hydrodynamics and bed level fluctuations, the different swash events were classified into events of type A and B and were then ensemble-averaged at time scale $T_{g}$ to study the intra-group dynamics. Type A is characterized by an uprush with high velocities followed by a weak wave-backwash interaction in which the backwash does not displace the 
next arriving wave seaward and a secondary uprush is observed; while type $\mathrm{B}$ is characterized by two waves merging during the uprush (wave capture) and a strong wave-backwash interaction in which the backwash sweeps the next arriving wave seaward. The presence of wave-swash interactions is deterministic and repeatable for bichromatic wave groups.

The suspended sediment dynamics for wave condition BE1 are highly controlled by onshore sediment advection from the lower swash region (location close to the rundown) to the upper swash regions (locations closer to the runup) during the uprush, resulting in erosion at the lower swash region during the uprush. In contrast, during the backwash sediment is advected seaward from the upper to lower swash region resulting in accretion at the lower swash region $(X=0.24 \mathrm{~m})$. The importance of cross-shore sediment advection on swash morphology has been addressed before and has been associated to suspended sediment settling lags due to enhanced turbulence and sediment trapped by turbulent bores (Alsina et al., 2009; Pritchard and Hogg, 2005). Incident bores arriving to the shoreline can be very efficient in mobilizing sediment from the bed (Alsina et al., 2009) due to large bed shear stresses (Barnes et al., 2009) and large turbulence levels (O'Donoghue et al., 2010). When the flow velocity and swash excursion is sufficiently large, turbulence and sediment is advected landward with the bore front during the uprush. During the backwash, bed-load sediment transport might be dominant but wave-backwash interacting events may bring the mobilized sediment into suspension. Strong wave-backwash events advect the mobilized sediment seaward while weak wave-backwash interactions result in locally onshore sediment transport.

The net bed level change (i.e. the bed level at the end of the swash event relative to the start of the event) is notably different for the two types of events: type A events induce a net (i.e. wave-group-averaged) erosion at the low swash region due to the large uprush dominance and the weakbackwash interaction reducing the seaward sediment advection during the backwash. On the other hand, type B events induce a net accretion at the lower swash region due to the less energetic wave-capture uprush and the strong wave-backwash interaction, which promotes the mobilization of sediment in the middle swash zone that is advected to the lower swash and potentially to the inner surf zone during the remainder of the backwash. Note that these patterns are observed from the high-pass filtered bed level measurements with the bed profile close to an equilibrium state. The overall trend of gradual bed level evolution for BE1 shows erosion at the lower swash, 
berm formation in the upper swash and a net export of sediment from the swash to the inner surf zone (Fig. 2). This trend was removed prior to ensemble-averaging the bed level measurements by the $\mathrm{CCM}^{+}$.

For wave condition BE4, the swash dynamics are largely controlled by the individual bores arriving to the shoreline. Consequently, the swash excursion is composed of individual swash events at the short-wave time scale, i.e. the swash excursions are of relatively short length and duration. The sediment response in terms of sand suspension and sheet flow layer thickness and transport is much weaker for this condition than for BE1. Also the amplitude of intra-swash bed level fluctuations is much smaller for BE4, indicating that the intra-swash cross-shore sediment exchange is weak. Although individual bore heights for BE4 are comparable to BE1, the sediment response is less pronounced. This is because larger bore heights occur at larger local water depth (induced by the low frequency component) so the bore turbulence has a smaller impact on the bed. Moreover, the highest incident bores arrive during the trough phase of the long-wave-induced velocity, hence leading to a reduction in uprush velocity magnitudes (Alsina et al., 2016). The relatively short duration and cross-shore extension of individual swash events for BE4 reduces the horizontal sediment exchange.

The measured beach profile evolution relates to these fundamental differences in sediment transport patterns found for conditions BE1 and BE4. For BE1 a larger shoreline retreat has been measured with a wider berm located further landward, as a consequence of the larger swash excursion and larger net sediment advection from the shoreline to the inner surf zone and to the berm. For BE4 the shoreline retreat is smaller with a narrower berm located closer to the initial shoreline as a result of the smaller swash excursions induced by the individual waves.

\subsection{Sheet-flow dynamics in the swash zone}

Previous studies on sheet flow layer dynamics in the swash zone showed vertical concentration profiles that are highly similar to sheet flow layers in oscillatory flows with similar grain size (Lanckriet et al., 2013, 2014; Puleo et al., 2016). On the other hand, van der Zanden et al. (2015) reported that due to the strongly non uniform cross-shore hydrodynamics in the swash zone, sheet flow layer concentrations may not be fully controlled by local vertical sediment exchange but instead, also by cross-shore advection. This alters the sheet flow layer structure in three ways: firstly, the sheet flow layer's pivot point may vary significantly at an intra-swash time scale; secondly, 
the concentration response in the erosion and upper sheet flow layers may not show the distinct "mirroring" pattern; thirdly, the sheet flow layer can be much thicker than expected based on the local instantaneous free-stream velocity forcing (van der Zanden et al., 2015).

In the present study the shortest wave group period, that produce swash events with a strong low-frequency motion (large excursion) due to bore focussing, drives a strong intra-swash cross-shore advection of sediment that affects the sheet flow layer, leading to a concentration response that differs from observations in oscillatory flows or in some previous swash studies (Lanckriet et al., 2013, 2014; Puleo et al., 2016). In contrast, when the horizontal swash excursion is smaller (as for the broad-banded BE4 wave condition) and the swash event oscillates at the time scale of the short incident waves, the sheet flow dynamics resemble previous observations in oscillatory flows (Ribberink et al., 2008; Dohmen-Janssen and Hanes, 2002, 2005; O'Donoghue and Wright, 2004) with an upper sheet flow layer that mirrors the pick up layer.

The inter-comparison of sheet flow layer measurements for wave conditions BE1 and BE4 especially shows the relevance of swash velocity and swash duration on the sheet flow dynamics. BE1, characterized by longer swash excursions and larger velocity magnitudes, produces much thicker sheet flow layers than condition BE4. Large sheet flow layer thickness for BE1 is observed during the long-duration, quasi-steady backwash that is characterized by strong wave-backwash interactions and the presence of stationary bores. Similarly, for BE4 the sheet flow layer develops clearly during the backwash stages, which are for this condition of short duration and associated with short waves. The arrival of incident waves during the backwash stages reduces flow speeds and interrupts the growth of the sheet flow layer. These interruptions may partly explain why the sheet flow layer thickness during the backwash stages is much smaller for condition BE4 than for BE1. This would imply that the sheet flow layer growth depends on backwash duration, with more developed (i.e. thicker) sheet flow layers and, consequently, higher offshore sheet flow transport for longer-duration and uninterrupted backwash events. Moreover, it suggests that the sheet flow layer can develop longer and reach higher thickness during quasi-steady backwash events than in unsteady oscillatory flows. Consequently, existing models for sheet flow layer thickness and transport developed for oscillatory flows may underestimate the thickness and transport rate during backwash stages. 


\section{Conclusion}

Large scale measurements of swash hydrodynamics, suspended sediment concentration and detailed sheet flow characteristics during wave-groupinduced swash events have been obtained. Repeatable wave groups were generated using controlled bichromatic wave conditions with the same energy content but with varying wave group period. Conditions BE1 (shortest wave group period) and BE4 (longest wave group period) result in notably different swash events. On the basis of these measurements, the following is concluded:

- A higher long wave amplitude and stronger bore focusing for the shortest wave group period (BE1) leads to swash events mostly varying at the group frequency and with a relatively high cross-shore excursion. In contrast, the longest wave group period (BE4) produces a series of swash events with limited cross-shore excursion and short duration, and that are primarily associated with the incident short waves.

- The different swash zone hydrodynamics are also reflected in the wave sequence and wave-swash interactions occurring at the swash zone. For BE4, the individual turbulent bores arrive at the shoreline with weak interactions with the preceding swash events. Condition BE1, on the other hand, produces energetic uprush events and a variety of waveswash interactions (wave capture, and strong and weak wave-backwash interactions).

- Uprush events can advect significant loads of sediment landward resulting in erosion close to the rundown location. The magnitude of the advected sediment load depends on onshore velocity, swash duration and swash excursion.

- A turbulent bore arriving to the swash overrunning a previous uprush (wave capture) is less efficient in mobilizing sediment than a single wave uprush event, probably because the presence of a swash column from the preceding wave reduces the bed shear stress and/or turbulence levels at the bed.

- The backwash can advect sediment from swash regions close to the maximum runup to the rundown, resulting in accretion around the rundown location. 
- A strong wave-backwash interacting event and the presence of a stationary bore enhances the turbulent resuspension of sediment and the seaward advection of sediment during the backwash. In contrast, a weak wave-swash interaction reduces the oshore advection of sediment from the berm to the rundown, promoting net erosion close to the rundown.

- The sheet flow layer has been found to be thickest during the late stage of the backwash and decreases immediately after the arrival of the next arriving bore.

- For swash events that are dominated by the low-frequency wave group motion (e.g. BE1), the sheet flow layer is dominated by horizontally advected sediment. In contrast, when the swash motion is controlled by the short waves (BE4), the sheet flow dynamics are dominated by local vertical exchange of sediment. In this case, the concentration behaviour in the sheet flow layer is very similar to oscillatory sheet flows.

- The two wave conditions produce significantly different beach-face evolution with a larger shoreline retreat and a wider berm located further onshore for the shortest wave group period (BE1) compared to the longest wave group period (BE4). These differences in bed profile evolution relate to the various complex intra-swash processes that were studied in detail.

- The wave group structure, sequence of individual waves and the presence of low frequency water surface oscillations are important variables controlling the sediment dynamics in the swash zone and the shape of the beach face.

\section{Acknowledgements}

The experimental part of this work was funded by the European Community's Seventh Framework Programme through the grant to the budget of the Integrating Activity HYDRALAB IV within the Transnational Access Activities, Contract no. 261520. We would like to thank the CIEM staff (Quim Sospedra, Ricardo Torres and Oscar Galego) for their assistance in running the experiments. The authors are also grateful to Professor Tom 
Baldock and an anonymous reviewer for their constructive comments on an earlier version of this paper.

\section{Appendix A. Variability about ensemble averaged values}

The use of bichromatic wave conditions with repeated wave groups allows performing ensemble averaging at the repetition period $T_{R}$. Ensemble averaging has been also performed using similar wave groups for BE1_1 wave condition. This section shows the variability in the performed ensemble averaging as standard deviation values or confidence intervals have not been displayed in previous sections for the sake of clarity.

Figure A.1 displays time series of water surface elevation, velocity, suspended sediment concentration and bed elevation obtained using $\mathrm{CCM}^{+}$ probe 3 (gray lines) and ensemble averaged values (solid thick lines) where time is made non-dimensional with the group period $T_{g}$. The ensemble means are calculated over the last 5 of a total of 7 hydrodynamic runs (30 minutes per hydrodynamic run) and over the repetition period $T_{R}$. The beach profile evolution is smaller during the last hydrodynamic runs; at $X=0.24 \mathrm{~m}$ the bed erodes $\approx 8 \mathrm{~cm}$ during the first 2 hydrodynamic runs and $\approx 2 \mathrm{~cm}$ during the last 5 hydrodynamics run. The standard deviation over the five runs in quasi-equilibrium was also calculated for water surface elevation $(0.029 \mathrm{~m})$, velocity $(0.25 \mathrm{~m} / \mathrm{s})$, suspended sediment concentration $\left(0.0011 \mathrm{~m}^{3} / \mathrm{m}^{3}\right)$ and high and low frequency measured bed level using $\mathrm{CCM}^{+}$probe $3(1.7 \mathrm{~mm}$ and $2.21 \mathrm{~mm}$ respectively). Similar variability mas measured for different crossshore locations. A total number of 65 cycles of $T_{R}$ have been used in the ensemble. The variability is relatively high for low frequency bed level measured with the $\mathrm{CCM}^{+}$probe 3 (band-pass filtered with cut-off frequencies of $0.004-0.02 \mathrm{~Hz}$ ). The low-frequency bed evolution is attributed to changes in phase of the wave groups repeating at $T_{R}$ resulting in repeated changes in the sediment transport. Small variations between swash events or crosstank asymmetries might have a relatively large impact on these repeating processes and on the low frequency bed evolution variability.

Figure A.2 shows a similar plot as Figure A.1 but ensemble averaging is performed over similar swash events denoted as type A and B events (see Section 5.1.1). The variability in swash events was again calculated by means of the standard deviation for the water surface elevation $(0.031 \mathrm{~m}$

for event $\mathrm{A}$ and $0.036 \mathrm{~m}$ for event B), velocity $(0.28 \mathrm{~m} / \mathrm{s}$ for event $\mathrm{A}$ and $0.25 \mathrm{~m} / \mathrm{s}$ for event B), suspended sediment concentration $\left(0.0029 \mathrm{~m}^{3} / \mathrm{m}^{3}\right.$ for 
event $\mathrm{A}$ and $0.0016 \mathrm{~m}^{3} / \mathrm{m}^{3}$ for event B) and high frequency bed elevation (1.8mm for event $\mathrm{A}$ and $1.6 \mathrm{~mm}$ for event $\mathrm{B})$. The variability is higher than for the ensemble-averaged measurements over the repeat period. However, the number of waves $(\approx 325)$ used to obtain the ensemble also increases and therefore the convergence of the ensemble averaged values should be similar. Figures A.2g, h also displays the pivot position computed using the O'Donoghue and Wright (2004) method which shows a similar behaviour as the direct measurement of the bed level with the CCM+ probe 3 .

Finally, the ensembles values and ensemble averaged values of water surface elevation, velocity, suspended sediment concentration and relative bed elevation for BE4_2 wave condition are illustrated in Figure A.3. The variability is similar to BE1 with standard deviation values of $0.018 \mathrm{~m}, 0.22 \mathrm{~m} / \mathrm{s}$, $0.0014 \mathrm{~m}^{3} / \mathrm{m}^{3}$ and $1.25 \mathrm{~mm}$ for water surface elevation, velocity suspended sediment concentration and bed elevation respectively. The pivot position computed using the O'Donoghue and Wright (2004) method is also displayed in Figure A.3.

\section{References}

Aagaard, T., Hughes, M. G., 2006. Sediment suspension and turbulence in the swash zone of dissipative beaches. Marine Geology 228 (1), 117 - 135.

Alsina, J. M., Caceres, I., 2011. Sediment suspension events in the inner surf and swash zone. measurements in large-scale and high-energy wave conditions. Coastal Engineering 58 (8), 657 - 670.

Alsina, J. M., Caceres, I., Brocchini, M., Baldock, T., 2012. An experimental study on sediment transport and bed evolution under different swash zone morphological conditions. Coastal Engineering 68, 31-43.

Alsina, J. M., Caceres, I., van der Zanden, J., Ribberink, J., Baldock, T., 2014. Large scale experiments on beach evolution induced by bichromatic wave groups with varying group period. Coastal Engineering Proceedings $1(34), 3$.

Alsina, J. M., Falchetti, S., Baldock, T. E., 2009. Measurements and modelling of the advection of suspended sediment in the swash zone by solitary waves. Coastal Engineering 56 (5), 621 - 631 . 
Alsina, J. M., Padilla, E. M., Caceres, I., 2016. Sediment transport and beach profile evolution induced by bi-chromatic wave groups with different group periods. Coastal Engineering 114, 325-340.

Baldock, T., Grayson, R., Torr, B., Power, H., 2014. Flow convergence at the tip and edges of a viscous swash front experimental and analytical modeling. Coastal Engineering 88, 123 - 130.

Baldock, T. E., Alsina, J. M., Caceres, I., Vicinanza, D., Contestabile, P., Power, H., Sanchez-Arcilla, A., 2011. Large-scale experiments on beach profile evolution and surf and swash zone sediment transport induced by long waves, wave groups and random waves. Coastal Engineering 58, 214227.

Baldock, T. E., Huntley, D. A., Bird, P. A. D., O’Hare, T., Bullock, G. N., 2000. Breakpoint generated surf beat induced by bichromatic wave groups. Coastal Engineering 39 (2), 213 - 242.

Barnes, M. P., O’Donoghue, T., Alsina, J. M., Baldock, T. E., 2009. Direct bed shear stress measurements in bore-driven swash. Coastal Engineering $56(8), 853-867$.

Blenkinsopp, C. E., Turner, I. L., Masselink, G., Russell, P. E., 2011. Swash zone sediment fluxes: Field observations. Coastal Engineering 58 (1), 28 44.

Brocchini, M., Baldock, T. E., 2008. Recent advances in modeling swash zone dynamics: Influence of surf-swash interaction on nearshore hydrodynamics and morphodynamics. Reviews of Geophysics 46 (3).

URL http://dx.doi.org/10.1029/2006RG000215

Brocchini, M., Gentile, R., 2001. Modelling the run-up of significant wave groups. Continental Shelf Research 21 (15), 1533 - 1550, nearshore and Coastal Oceanography.

Butt, T., Russell, P., 1999. Suspended sediment transport mechanisms in high-energy swash. Marine Geology 161 (2), 361 - 375.

Caceres, I., Alsina, J. M., 2012. A detailed, event-by-event analysis of suspended sediment concentration in the swash zone. Continental Shelf Research 41, 61-76. 
Caceres, I., Alsina, J. M., 2016. Suspended sediment transport and beach dynamics induced by monochromatic conditions, long waves and wave groups. Coastal Engineering 108, 36 - 55.

Chardon-Maldonado, P., Pintado-Patiño, J. C., Puleo, J. A., 2016. Advances in swash-zone research: Small-scale hydrodynamic and sediment transport processes. Coastal Engineering 115, 8 - 25, swash-zone Processes.

Chen, B.-T., Kikkert, G. A., Pokrajac, D., Dai, H.-J., 2016. Experimental study of bore-driven swashswash interactions on an impermeable rough slope. Coastal Engineering 108, $10-24$.

Dohmen-Janssen, C. M., Hanes, D. M., 2002. Sheet flow dynamics under monochromatic nonbreaking waves. Journal of Geophysical Research: Oceans 107 (C10), 13-1-13-21, 3149.

Dohmen-Janssen, C. M., Hanes, D. M., 2005. Sheet flow and suspended sediment due to wave groups in a large wave flume. Continental Shelf Research 25 (3), $333-347$.

Elgar, S., Guza, R. T., 1985. Observations of bispectra of shoaling surface gravity waves. Journal of Fluid Mechanics 161, 425448.

Erikson, L., Larson, M., Hanson, H., 2005. Prediction of swash motion and run-up including the effects of swash interaction. Coastal Engineering $52(3), 285-302$.

Guedes, R. M. C., Bryan, K. R., Coco, G., 2013. Observations of wave energy fluxes and swash motions on a low-sloping, dissipative beach. Journal of Geophysical Research: Oceans 118 (7), 3651-3669.

Guza, R. T., Feddersen, F., 2012. Effect of wave frequency and directional spread on shoreline runup. Geophysical Research Letters 39 (11), n/a-n/a.

Hughes, M. G., Moseley, A. S., 2007. Hydrokinematic regions within the swash zone. Continental Shelf Research 27 (15), 2000 - 2013.

Lanckriet, T., Puleo, J. A., 2015. A semianalytical model for sheet flow layer thickness with application to the swash zone. Journal of Geophysical Research: Oceans 120 (2), 1333-1352. 
Lanckriet, T., Puleo, J. A., Masselink, G., Turner, I. L., Conley, D., Blenkinsopp, C., Russell, P., 2014. Comprehensive field study of swash-zone processes. ii: Sheet flow sediment concentrations during quasi-steady backwash. Journal of Waterway, Port, Coastal, and Ocean Engineering 140 (1), 29-42.

Lanckriet, T., Puleo, J. A., Waite, N., 2013. A conductivity concentration profiler for sheet flow sediment transport. IEEE Journal of Oceanic Engineering 38 (1), 55-70.

Martins, K., Blenkinsopp, C. E., Almar, R., Zang, J., 2017. The influence of swash-based reflection on surf zone hydrodynamics: a wave-by-wave approach. Coastal Engineering 122, $27-43$.

Masselink, G., Evans, D., Hughes, M. G., Russell, P., 2005. Suspended sediment transport in the swash zone of a dissipative beach. Marine Geology 216 (3), $169-189$.

Masselink, G., Puleo, J. A., 2006. Swash-zone morphodynamics. Continental Shelf Research 26 (5), $661-680$.

Masselink, G., Russell, P., Turner, I., Blenkinsopp, C., 2009. Net sediment transport and morphological change in the swash zone of a high-energy sandy beach from swash event to tidal cycle time scales. Marine Geology 267 (1), $18-35$.

McLean, S. R., Ribberink, J. S., Dohmen-Janssen, C. M., Hassan, W. N., 2001. Sand transport in oscillatory sheet flow with mean current. Journal of Waterway, Port, Coastal, and Ocean Engineering 127 (3), 141-151.

Mieras, R. S., Puleo, J. A., Anderson, D., Cox, D. T., Hsu, T.-J., 2017. Largescale experimental observations of sheet flow on a sandbar under skewedasymmetric waves. Journal of Geophysical Research: Oceans 122 (6), 50225045 .

Moura, T., Baldock, T. E., 2018. New evidence of breakpoint forced long waves: Laboratory, numerical, and field observations. Journal of Geophysical Research: Oceans 0 (0). 
O’Donoghue, T., Kikkert, G. A., Pokrajac, D., Dodd, N., Briganti, R., 2016. Intra-swash hydrodynamics and sediment flux for dambreak swash on coarse-grained beaches. Coastal Engineering 112, 113 - 130.

O’Donoghue, T., Pokrajac, D., Hondebrink, L. J., 2010. Laboratory and numerical study of dambreak-generated swash on impermeable slopes. Coastal Engineering 57 (5), 513 - 530 .

O'Donoghue, T., Wright, S., 2004. Concentrations in oscillatory sheet flow for well sorted and graded sands. Coastal Engineering 50, 117-138.

Padilla, E. M., Alsina, J. M., 2017. Transfer and dissipation of energy during wave group propagation on a gentle beach slope. Journal of Geophysical Research: Oceans 122 (8), 6773-6794.

Pritchard, D., Hogg, A. J., 2005. On the transport of suspended sediment by a swash event on a plane beach. Coastal Engineering 52 (1), $1-23$.

Pujara, N., Liu, P. L.-F., Yeh, H. H., 2015. An experimental study of the interaction of two successive solitary waves in the swash: A strongly interacting case and a weakly interacting case. Coastal Engineering 105, 66 74 .

Puleo, J. A., Beach, R. A., Holman, R. A., Allen, J. S., 2000. Swash zone sediment suspension and transport and the importance of bore-generated turbulence. Journal of Geophysical Research: Oceans 105 (C7), 1702117044 .

Puleo, J. A., Lanckriet, T., Blenkinsopp, C., 2014. Bed level fluctuations in the inner surf and swash zone of a dissipative beach. Marine Geology 349, $99-112$.

Puleo, J. A., Lanckriet, T., Conley, D., Foster, D., 2016. Sediment transport partitioning in the swash zone of a large-scale laboratory beach. Coastal Engineering 113, 73 - 87, barrier Dynamics Experiment II: sediment processes across a large-scale sand barrier.

Ribberink, J. S., van der Werf, J. J., O’Donoghue, T., Hassan, W. N. M., 2008. Sand motion induced by oscillatory flows: Sheet flow and vortex ripples. Journal of Turbulence 9, N20. 
Schretlen, J. L. M., 2012. Sand transport under full-scale progressive surface waves. Ph.D. thesis, University of Twente, Enschede.

Sheremet, A., Staples, T., Ardhuin, F., Suanez, S., Fichaut, B., 2014. Observations of large infragravity wave runup at banneg island, france. Geophysical Research Letters 41 (3), 976-982.

Stockdon, H. F., Holman, R. A., Howd, P. A., Sallenger, A. H., 2006. Empirical parameterization of setup, swash, and runup. Coastal Engineering $53(7), 573-588$.

Tissier, M., Bonneton, P., Michallet, H., Ruessink, B. G., 2015. Infragravitywave modulation of short-wave celerity in the surf zone. Journal of Geophysical Research: Oceans 120 (10), 6799-6814.

van der Zanden, J., Alsina, J. M., Caceres, I., Buijsrogge, R., Ribberink, J., 2015. Bed level motions and sheet flow processes in the swash zone: Observations with a new conductivity-based concentration measuring technique $\left(\mathrm{ccm}^{+}\right)$. Coastal Engineering 105, 47-65.

van der Zanden, J., van der A, D. A., Hurther, D., Caceres, I., O'Donoghue, T., Hulscher, S. J. M. H., Ribberink, J. S., 2017. Bedload and suspended load contributions to breaker bar morphodynamics. Coastal Engineering $129,74-92$.

Wu, L., Feng, D., Shimozono, T., Okayasu, A., 2016. Laboratory measurements of sediment flux and bed level evolution in the swash zone. Coastal Engineering Journal 58 (02), 1650004. 
Table 1: Instrument locations

\begin{tabular}{|c|c|c|}
\hline Sensor & $\mathrm{N}^{o}$ & $\begin{array}{l}\text { Cross-shore position (in } \mathrm{m} \text { ) with respect to the wave paddle } \\
\text { location }\left(X_{a}\right) \text {. In parenthesis, vertical elevation with respect } \\
\text { to the bed level }\end{array}$ \\
\hline WG & 12 & $\begin{array}{l}7.72,26.98,28.48,30.55,44.54,47.54,50.57,53.57,56.59, \\
59.57,62.63,65.61\end{array}$ \\
\hline AWG & 8 & $75.10,75.86,76.93,77.89,78.41,79.27,80.24,81.34$ \\
\hline PPT & 8 & 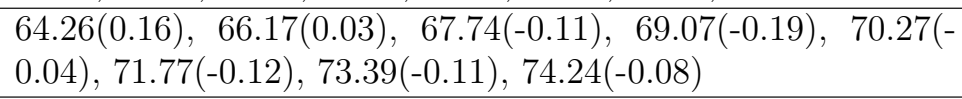 \\
\hline ADV & 7 & $\begin{array}{l}71.85(0.05), 73.44(0.05), 74.82(0.05), 75.36(0.05), 75.81(0.03), \\
76.91(0.03), 77.85(0.03)\end{array}$ \\
\hline OBS & 8 & $\begin{array}{l}\text { 71.85(0.05), 73.44(0.05), 74.82(0.05), 75.36(0.05), 75.81(0.03), } \\
76.91(0.03), 77.85(0.03)\end{array}$ \\
\hline $\begin{array}{l}\mathrm{CCM}^{+} \\
\text {tanks }\end{array}$ & 2 & $75.81,77.84$ \\
\hline
\end{tabular}

Table 2: Bichromatic wave group conditions

\begin{tabular}{l|cccccl}
\hline \multirow{2}{*}{ Wave conditions } & \multicolumn{7}{|c}{ Component 1 } & \multicolumn{2}{c}{ Component 2 } \\
& $H_{1}(\mathrm{~m})$ & $f_{1}(\mathrm{~Hz})$ & $H_{2}(\mathrm{~m})$ & $f_{2}(\mathrm{~Hz})$ & $T_{g}(\mathrm{~s})$ & $d(\mathrm{~m})$ \\
\hline BE1_1 & 0.29 & 0.303 & 0.26 & 0.237 & 15.00 & 2.53 \\
BE1_2 & 0.30 & 0.303 & 0.26 & 0.237 & 15.00 & 2.48 \\
BE4_1 & 0.29 & 0.288 & 0.27 & 0.252 & 27.70 & 2.50 \\
BE4_2 & 0.28 & 0.288 & 0.30 & 0.252 & 27.70 & 2.46 \\
\hline
\end{tabular}




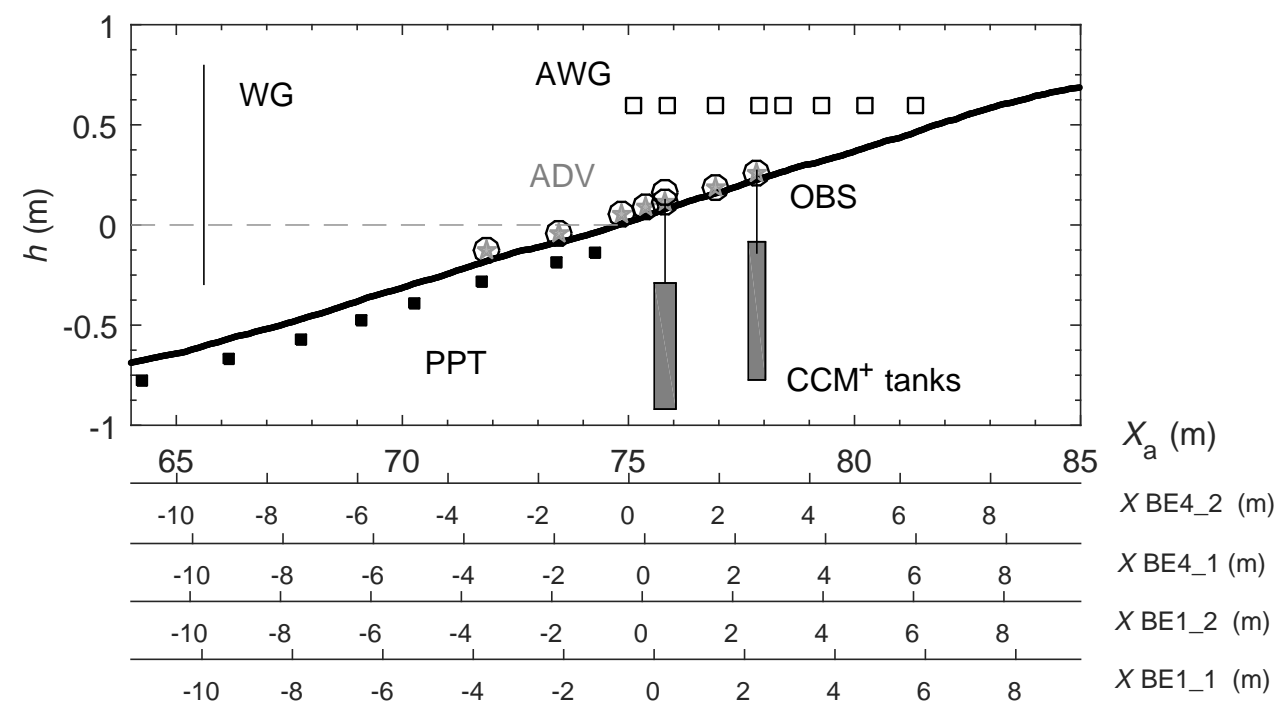

Figure 1: Wave flume layout with instrument locations at fixed cross-shore coordinate system $X_{a}$ and coordinate system relative to the initial SWL location $X$. 

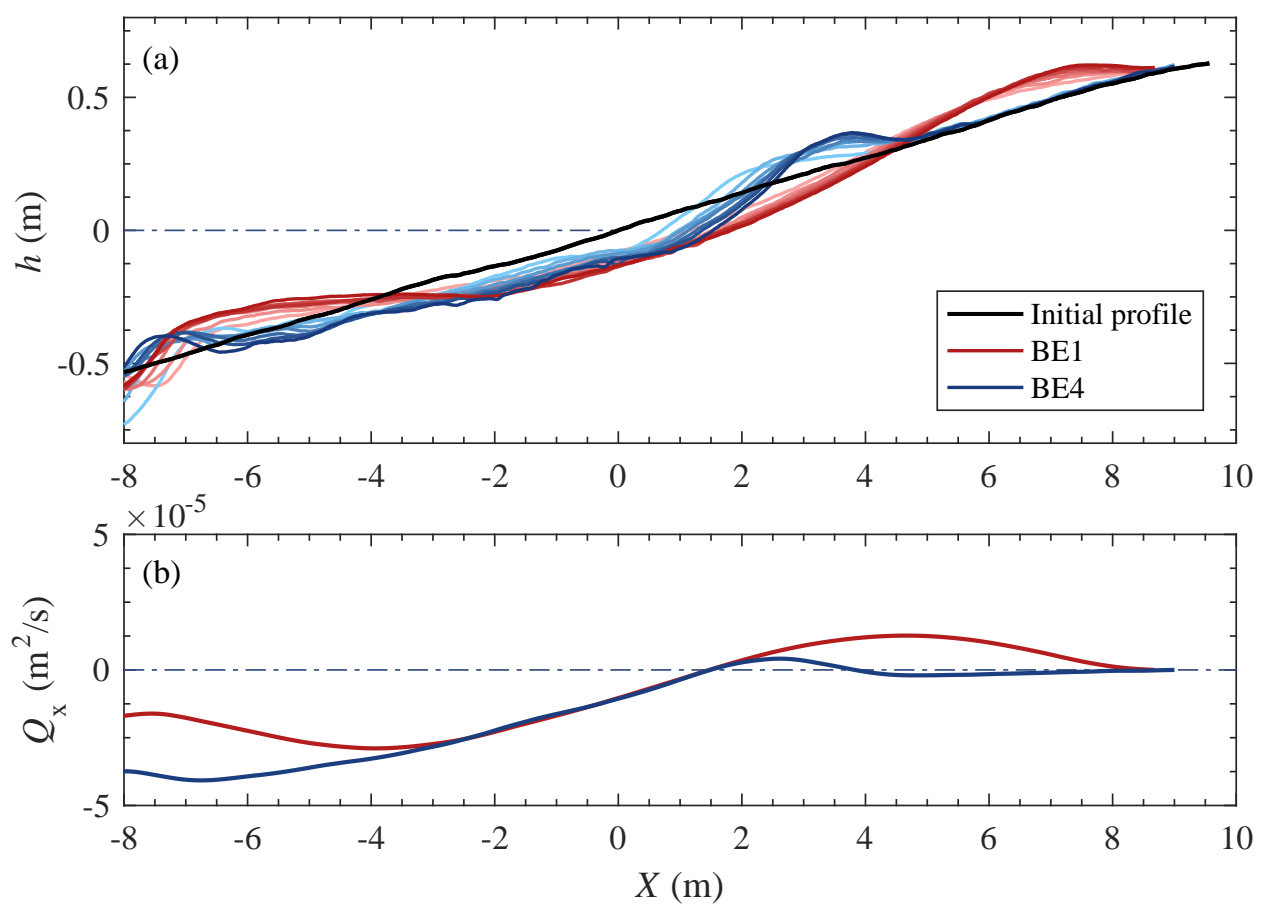

Figure 2: Beach profile evolution (a) for wave conditions BE1 and BE4 where each line corresponds to the profile measured after 30 min of successive wave action with colours changing from light to dark as time progresses; and computed sediment transport rates after 210 min of wave action (b). 

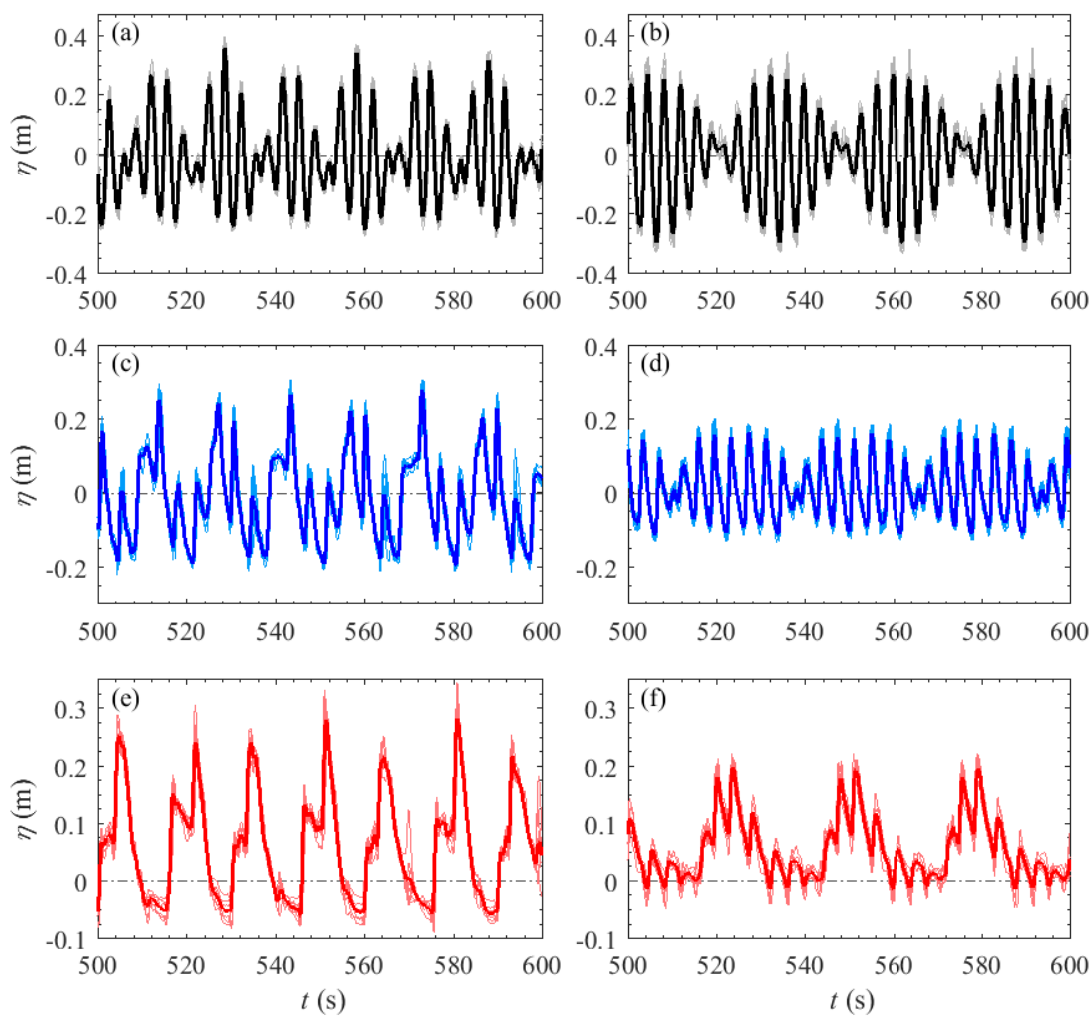

Figure 3: Water surface elevation time series for wave conditions BE1_1 (left) and BE4_2 (right) at cross-shore locations: $X=-67.85 \mathrm{~m}$ (a), $X=-67.04 \mathrm{~m}$ (b), $X=-9.40 \mathrm{~m}$ (c), $X=-8.59 \mathrm{~m}(\mathrm{~d}), X=0.24 \mathrm{~m}$ (e) and $X=1.04 \mathrm{~m}$ (f). Light-coloured lines indicate values for each of the hydrodynamic runs and dark lines indicate ensemble average. 

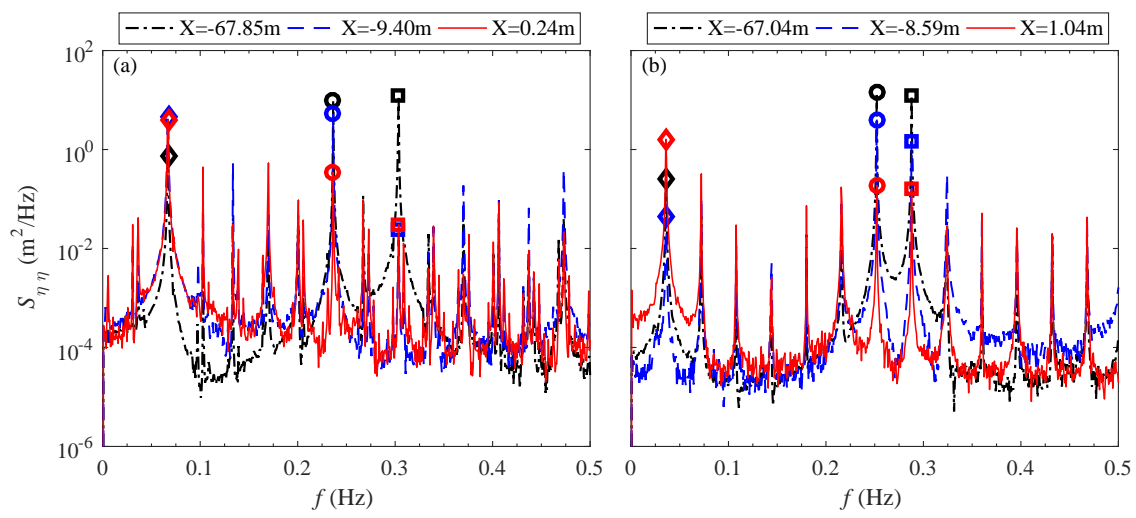

Figure 4: Power spectrum density plots of water surface elevation for wave conditions BE1_1 (a) and BE4_2 (b) at the same cross-shore locations as in Figure 3 where same line colors than in Figure 3 indicate same cross-shore location. $\diamond$ symbol corresponds to $f_{g}$, $\circ$ to $f_{2}$ and $\square$ to $f_{1}$ (For a color figure, the reader is referred to the web version of this article).

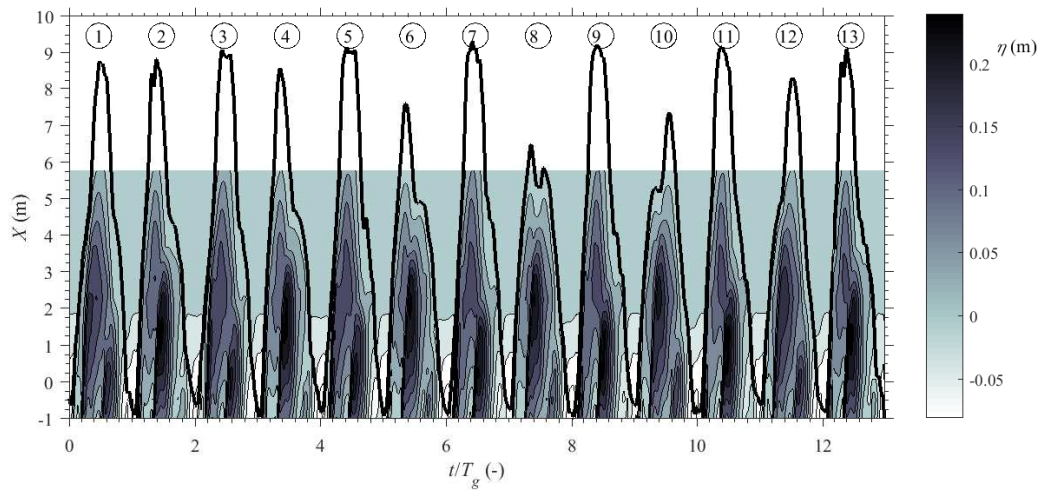

Figure 5: Contour plot of ensemble averaged water surface elevation in non-dimensional time (horizontal axis) and cross-shore distance (vertical axis) for wave condition BE1_1. Solid thick line indicates the time-dependent shore-line position. 

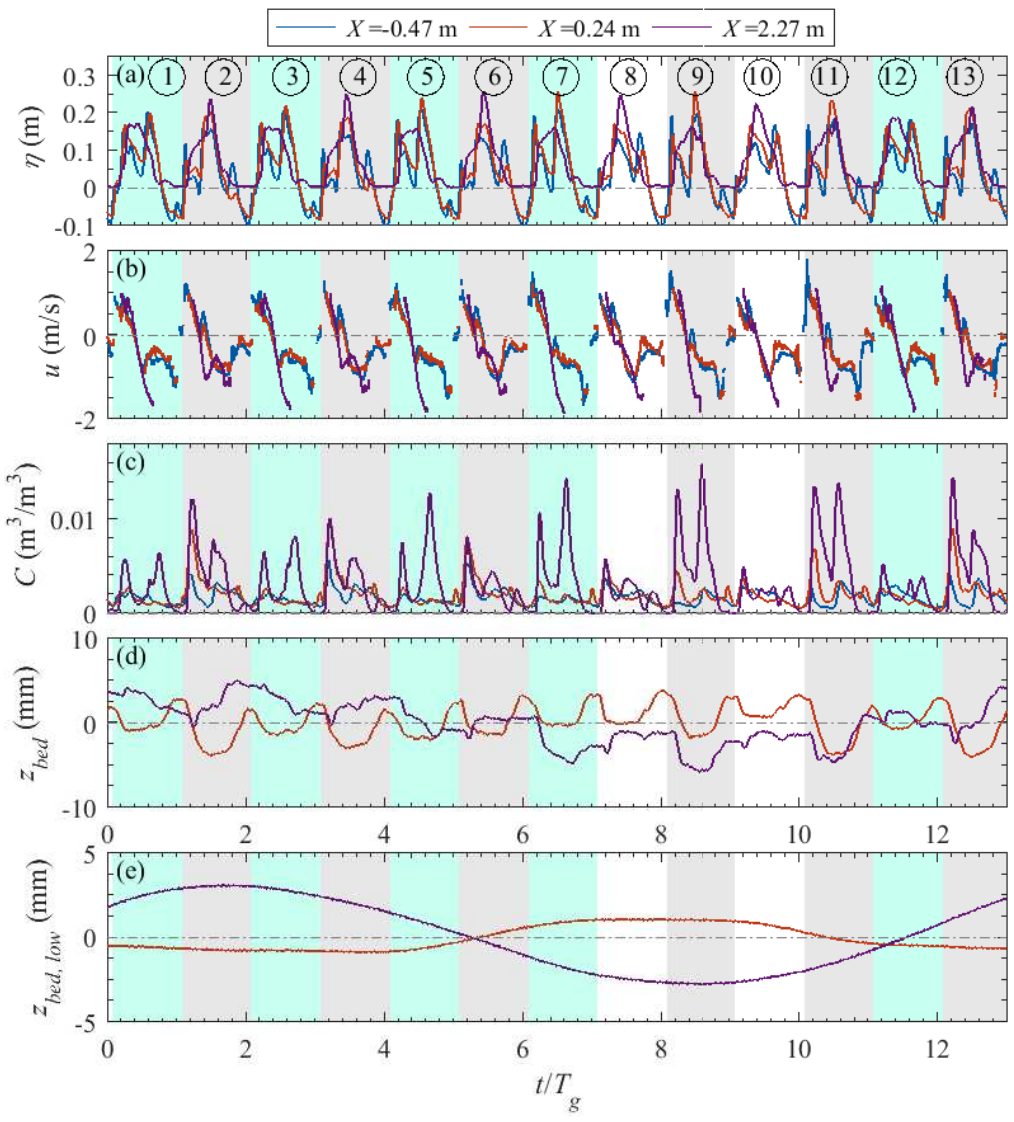

Figure 6: Time series of ensemble-averaged water surface elevation (a), horizontal velocity (b), suspended sediment concentration (c), high-pass filtered bed level measurement (cutoff frequency $0.004 \mathrm{~Hz}$ ) by $\mathrm{CCM}^{+}$probe 3 and 4 (d) and bed level measurement, band-pass filtered (cut off frequencies $0.004-0.020 \mathrm{~Hz}$ ) (e) for condition BE1_1. Wave groups of type A are illustrated with a grey shade and wave groups of type B with a blue shade. 


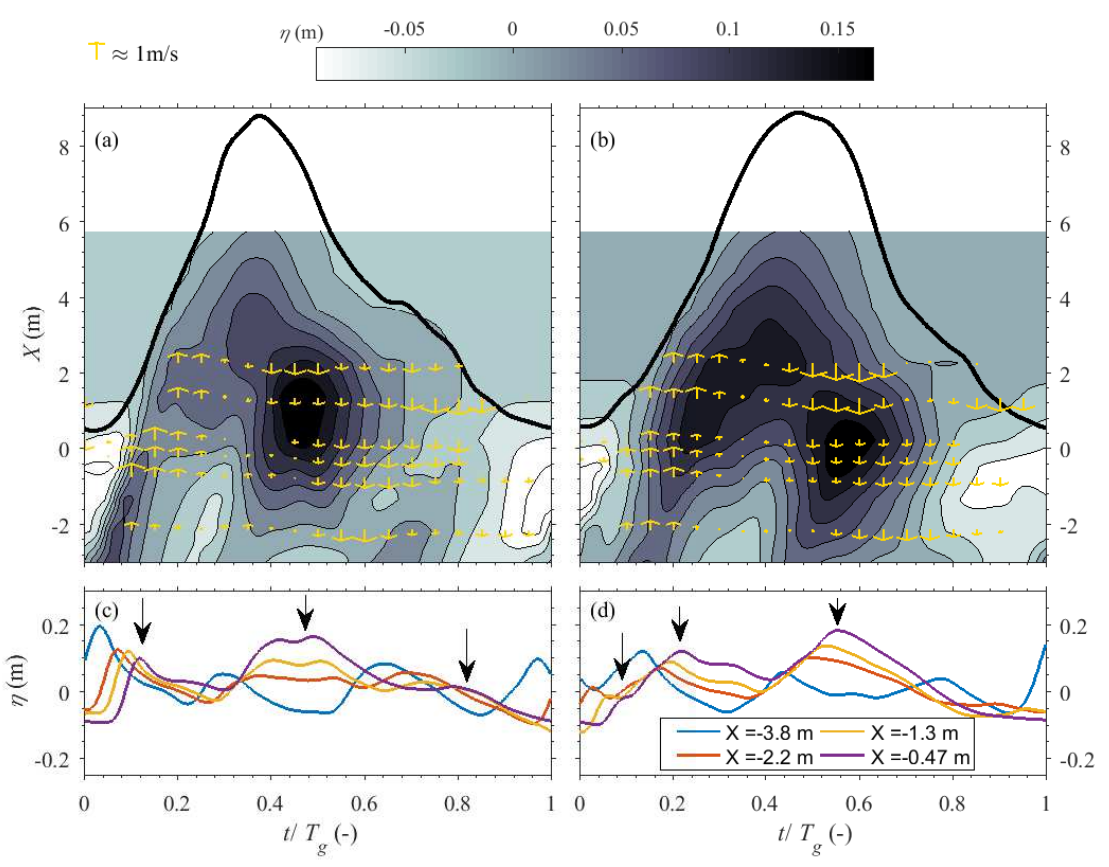

Figure 7: Distribution of ensemble averaged water surface elevation, $\eta$ in the inner surf zone and swash zone for wave condition BE1_1. Ensemble averaging is performed over swash events of type A (left plots) and B (right plots). Plots (a) and (b) show $\eta$ contour plot distribution in non-dimensional time, $t / T_{g}$, (horizontal axis) and cross-shore distance (vertical axis) where the solid thick line indicates the time-dependent shore-line position and vectors indicate horizontal velocity. Plots (c) and (d) show time series of water surface elevation around the inner surf/swash limit with the arrows highlighting the arrival of the individual waves at $X=-0.47 \mathrm{~m}$. 

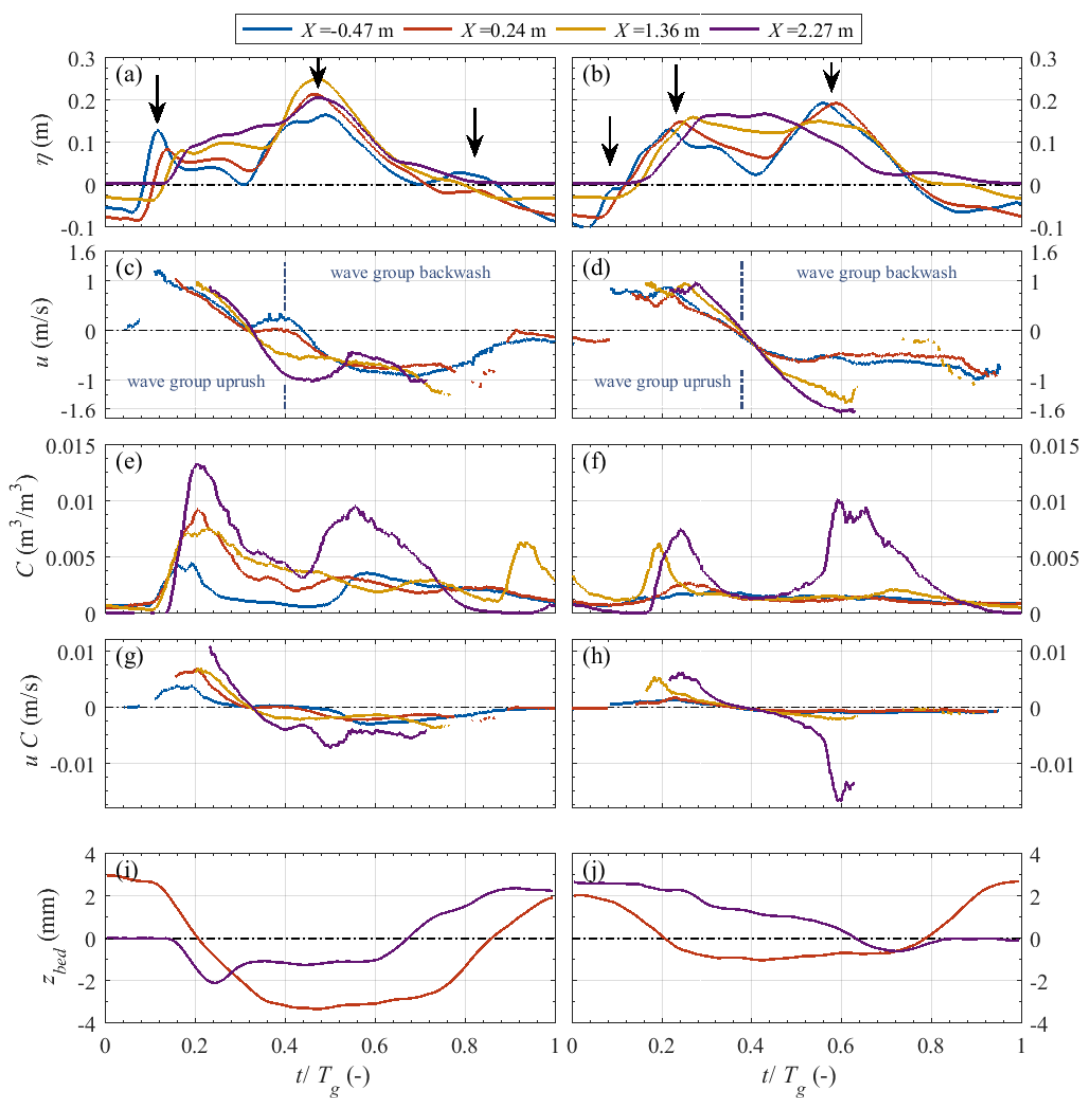

Figure 8: Time series of ensemble-averaged water surface elevation ( $a, b)$, horizontal velocity $(\mathrm{c}, \mathrm{d})$, suspended sediment concentration $(\mathrm{e}, \mathrm{f})$, sediment fluxes $u C(\mathrm{~g}-\mathrm{h})$ and bed elevation measured with $\mathrm{CCM}^{+}$, high-pass filtered (cut off frequency $0.020 \mathrm{~Hz}$ ) $(\mathrm{i}, \mathrm{j}$ ) for wave condition BE1_1. Left and right plots correspond to type A and B swash events. Arrows indicate the arrival of the individual waves at $X=-0.47 \mathrm{~m}$ as in Figure 7 . The cross-shore locations $X=-0.47,0.24,1.36,2.27 \mathrm{~m}$ in non-dimensional form relative to the mean maximum horizontal $\operatorname{runup}(R u=7.29 \mathrm{~m})$ are $X / R u=-0.06,0.03,0.19,0.31$ respectively. 


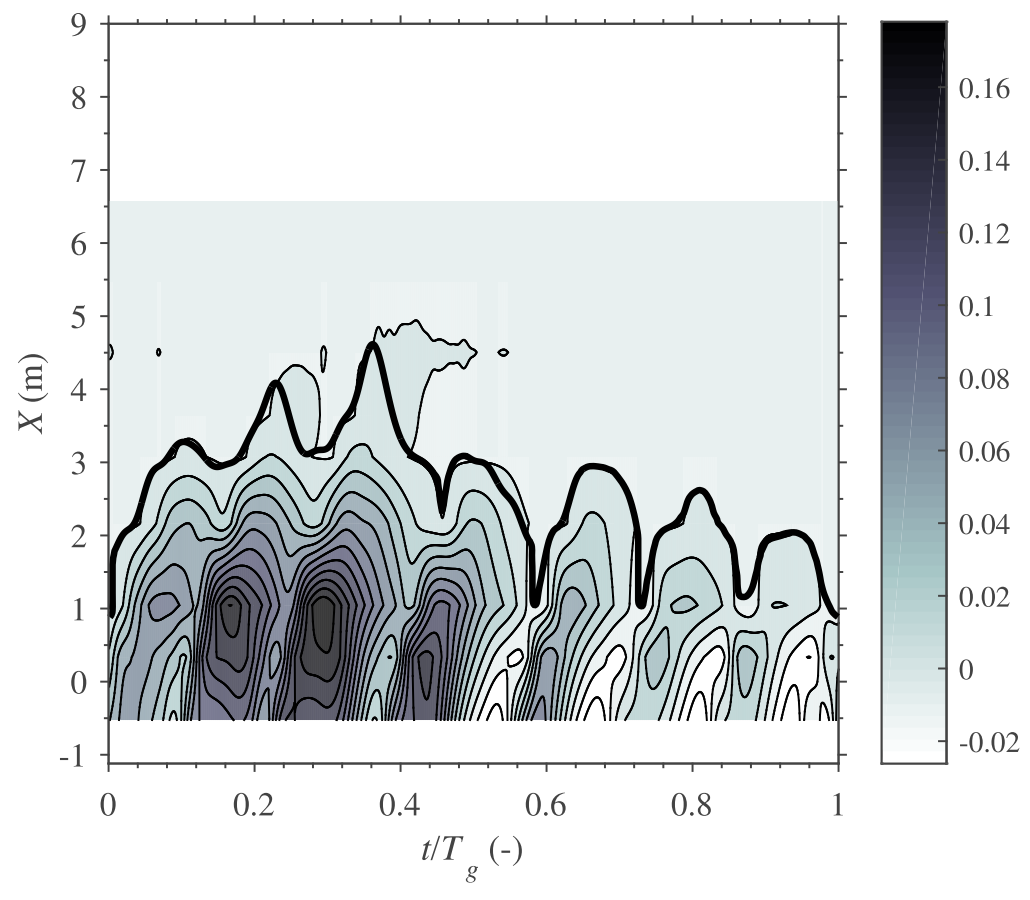

Figure 9: Contour plot of ensemble-averaged water surface elevation, including time dependent shore-line position (solid thick line), for wave condition BE4_2. 

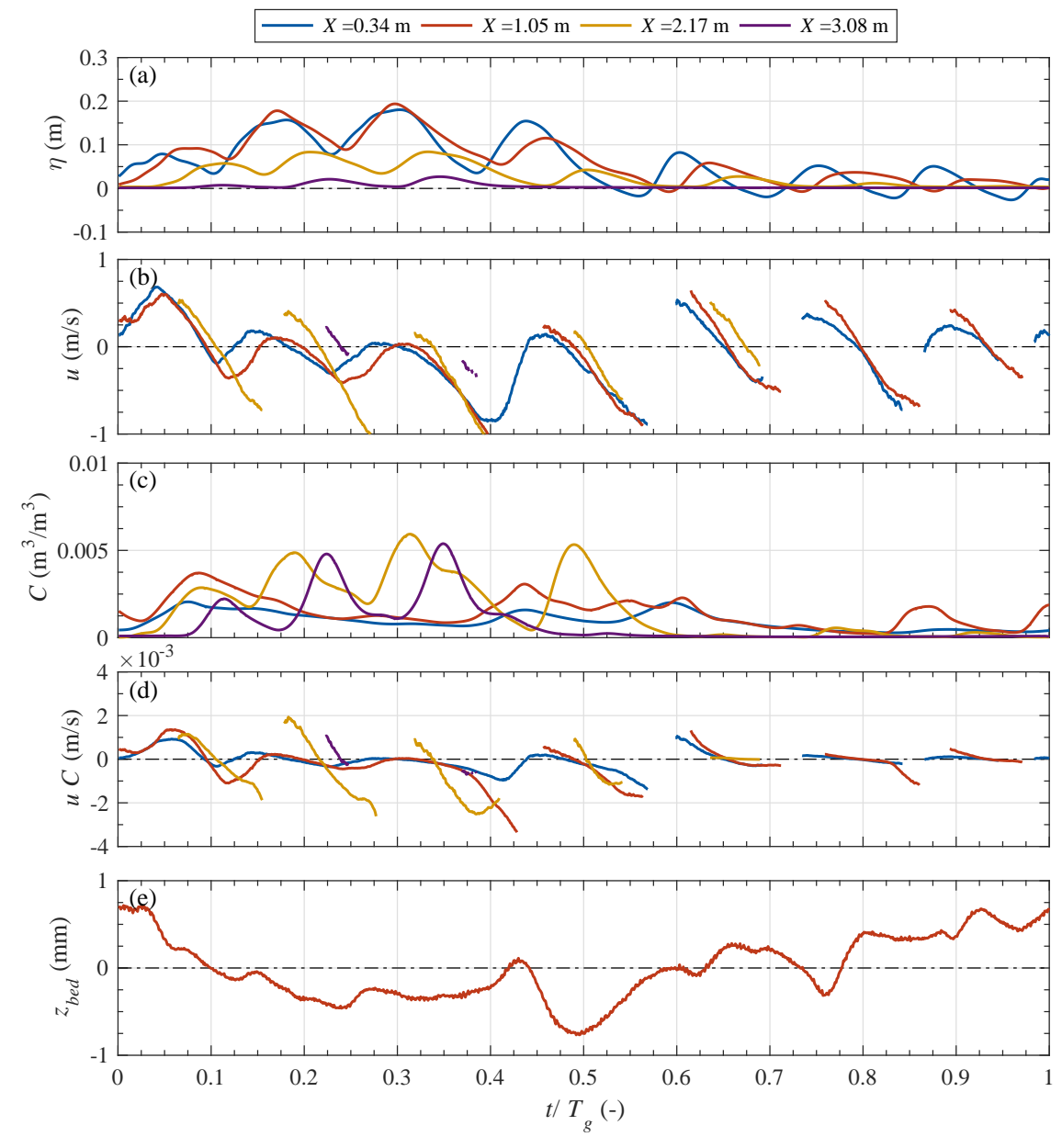

Figure 10: Time series of ensemble-averaged water surface elevation (a), horizontal velocity (b), suspended sediment concentration (c), sediment fluxes $u C$ (d), and bed elevation measured with $\mathrm{CCM}^{+}$probe 3 , high-pass filtered (cut off frequency $0.020 \mathrm{~Hz}$ ) (e) for wave conditions BE4_2. Note that the y axes have different scales than Figure 8. The cross-shore locations $X=0.34,1.05,2.17$ and $3.08 \mathrm{~m}$ in non-dimensional form relative to the maximum horizontal runup $(R u=4.62 \mathrm{~m})$ are $X / R u=0.07,0.23,0.47$ and 0.67 respectively. 

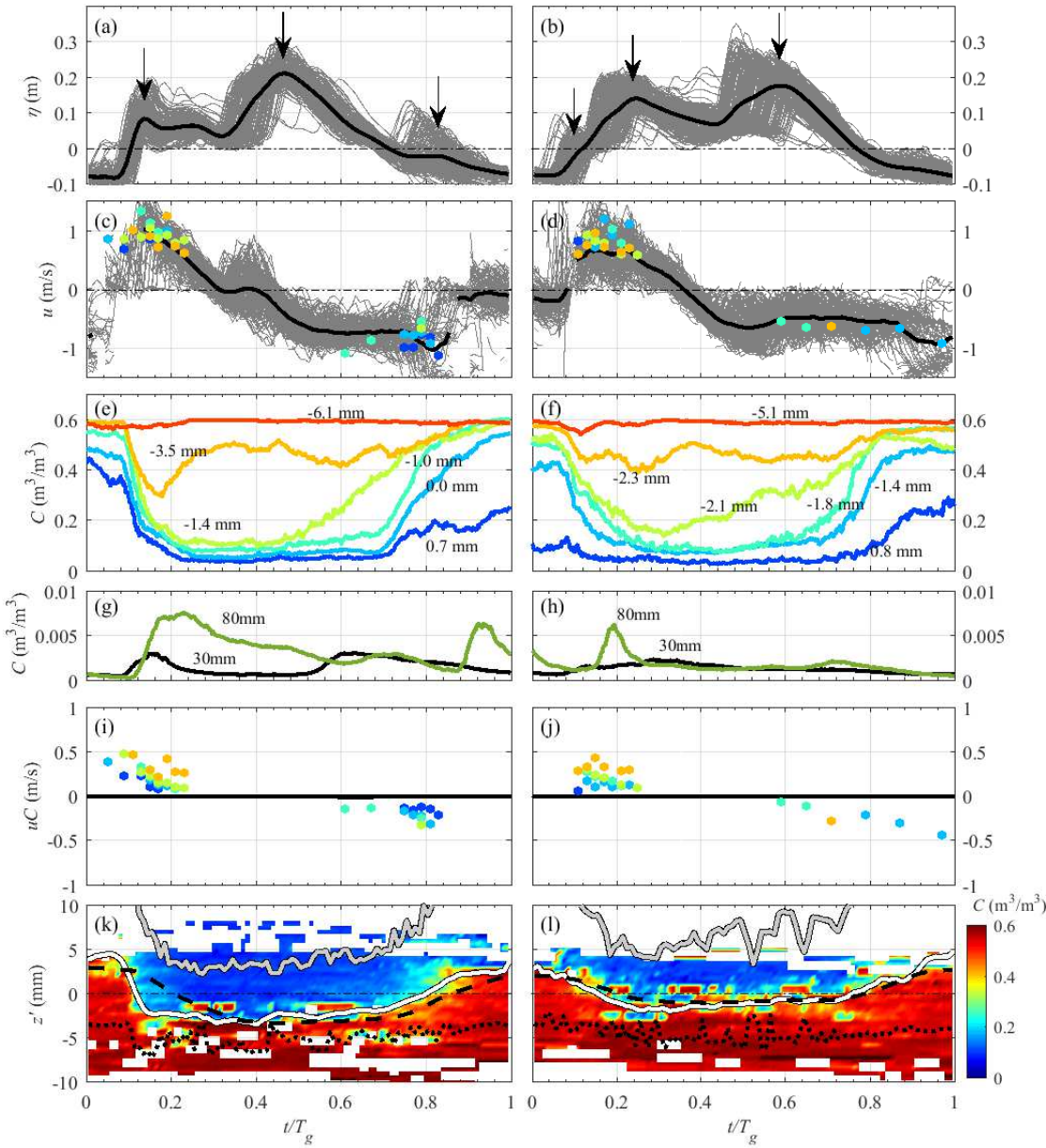

Figure 11: Time series of ensemble-averaged measurements for condition BE1_1 at $X=0.24 \mathrm{~m}$, type A (left) and B (right) swash events: water surface elevation (a,b), horizontal water and sediment particle velocity with different concentration value indicated by the color bar $(\mathrm{c}, \mathrm{d})$, sediment concentration in the sheet flow layer $(\mathrm{e}, \mathrm{f})$, suspended sediment concentration $(\mathrm{g}, \mathrm{h})$, sediment fluxes $(\mathrm{i}, \mathrm{j})$ and contour plot of sediment concentration measured by $\mathrm{CCM}^{+}$including elevations of sheet flow layer top (solid gray line), bottom (dotted line), and pivot point using O'Donoghue and Wright (2004) fit (solid white line), and the direct bed elevation measured by $\mathrm{CCM}^{+}$(dashed line) $(\mathrm{k}, \mathrm{l})$. The colours and concentration values in plots (c-f, $\mathrm{i}-\mathrm{l})$ are indicated by the colour bar. Arrows in plots (a) and (b) indicate the arrival of the individual waves at $X=0.24 \mathrm{~m}$. 

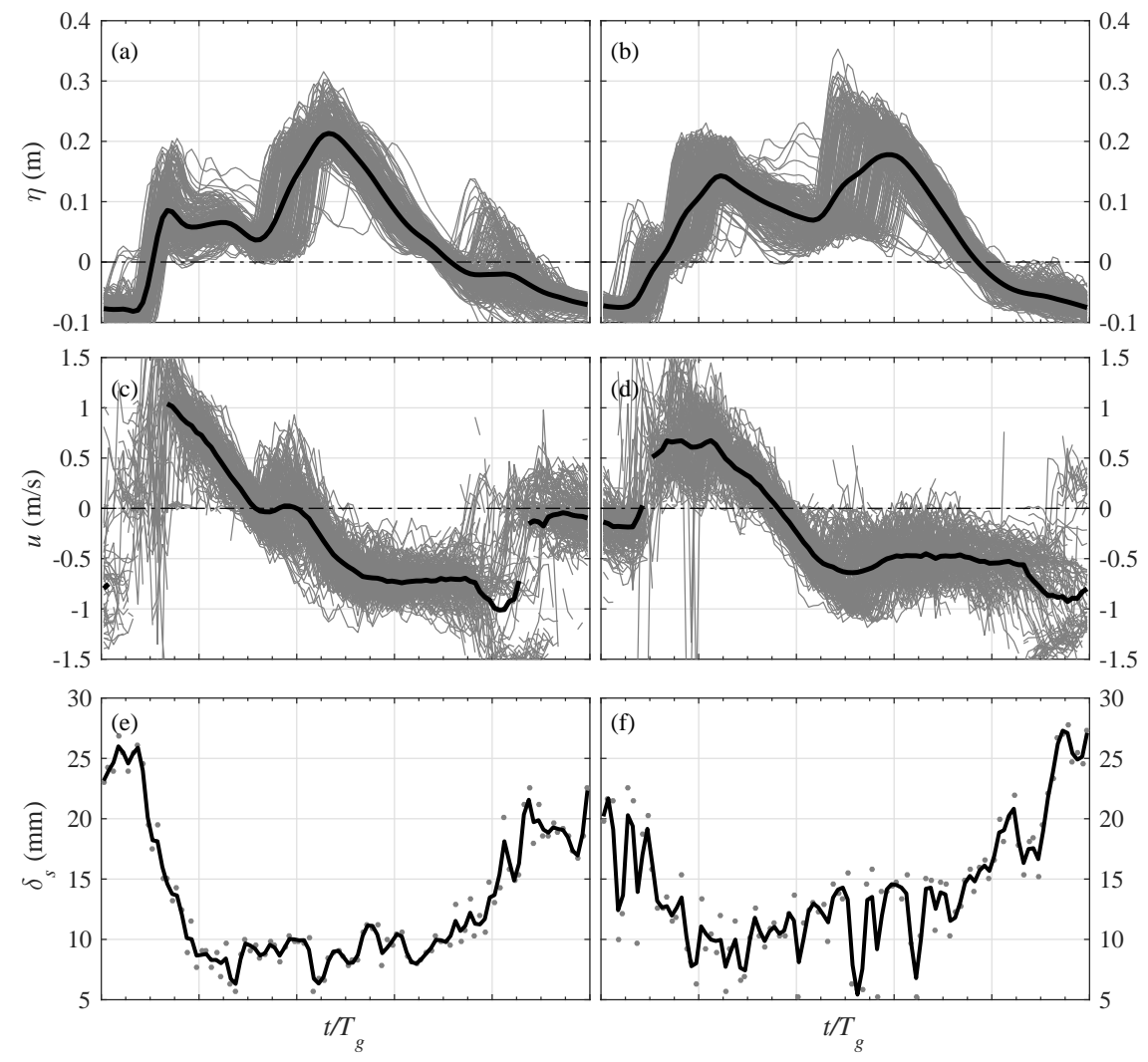

Figure 12: Time series of ensemble-averaged water surface elevation $(\mathrm{a}, \mathrm{b})$, horizontal water velocity $(\mathrm{c}, \mathrm{d})$ and sheet-flow layer thickness (dots are measured data and solid line a polynomial fit to data) (e,f) at $X=0.24 \mathrm{~m}$, for wave condition BE1_1 and type A (left) and $\mathrm{B}$ (right) swash events. 


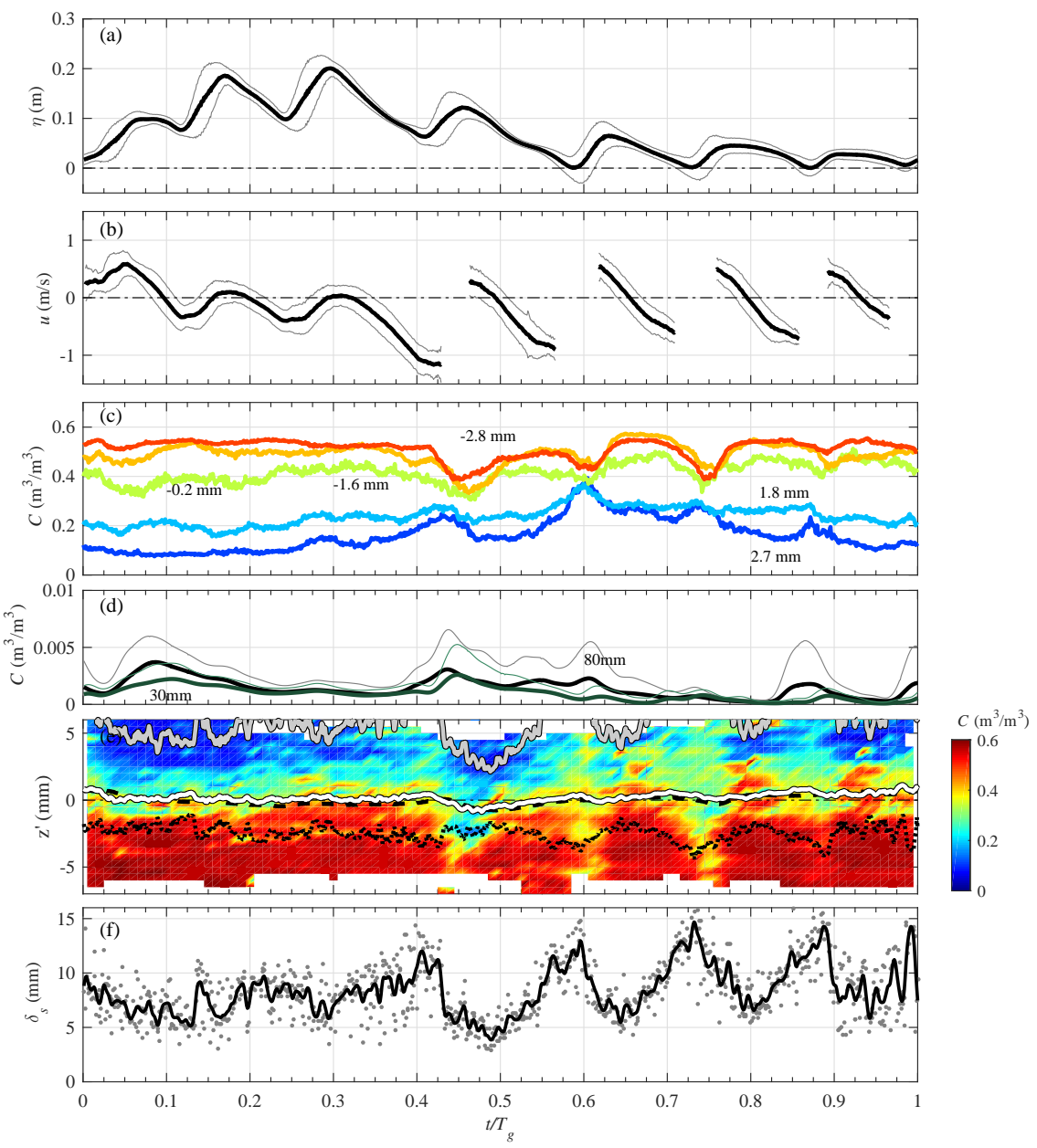

Figure 13: Time series of ensemble-averaged water surface elevation $+/$-standard deviation (a), horizontal water velocity $+/$ - standard deviation (b) sediment concentration in the sheet flow layer (c), suspended sediment concentration + standard deviation (d), contour plot of sediment concentration measured by $\mathrm{CCM}^{+}$including elevations of sheet flow layer top (solid gray line), bottom (dotted line), and pivot point using O'Donoghue and Wright (2004) fit (solid white line), and the direct bed elevation measured by $\mathrm{CCM}^{+}$(dashed line) (e); and sheet flow layer thickness (dots are measured data and solid line a polynomial fit to data) (f) for wave condition BE4_2 obtained at $X=1.05 \mathrm{~m}$. The colours and concentration values in plots (c) and (d) are indicated by the colour bar. 

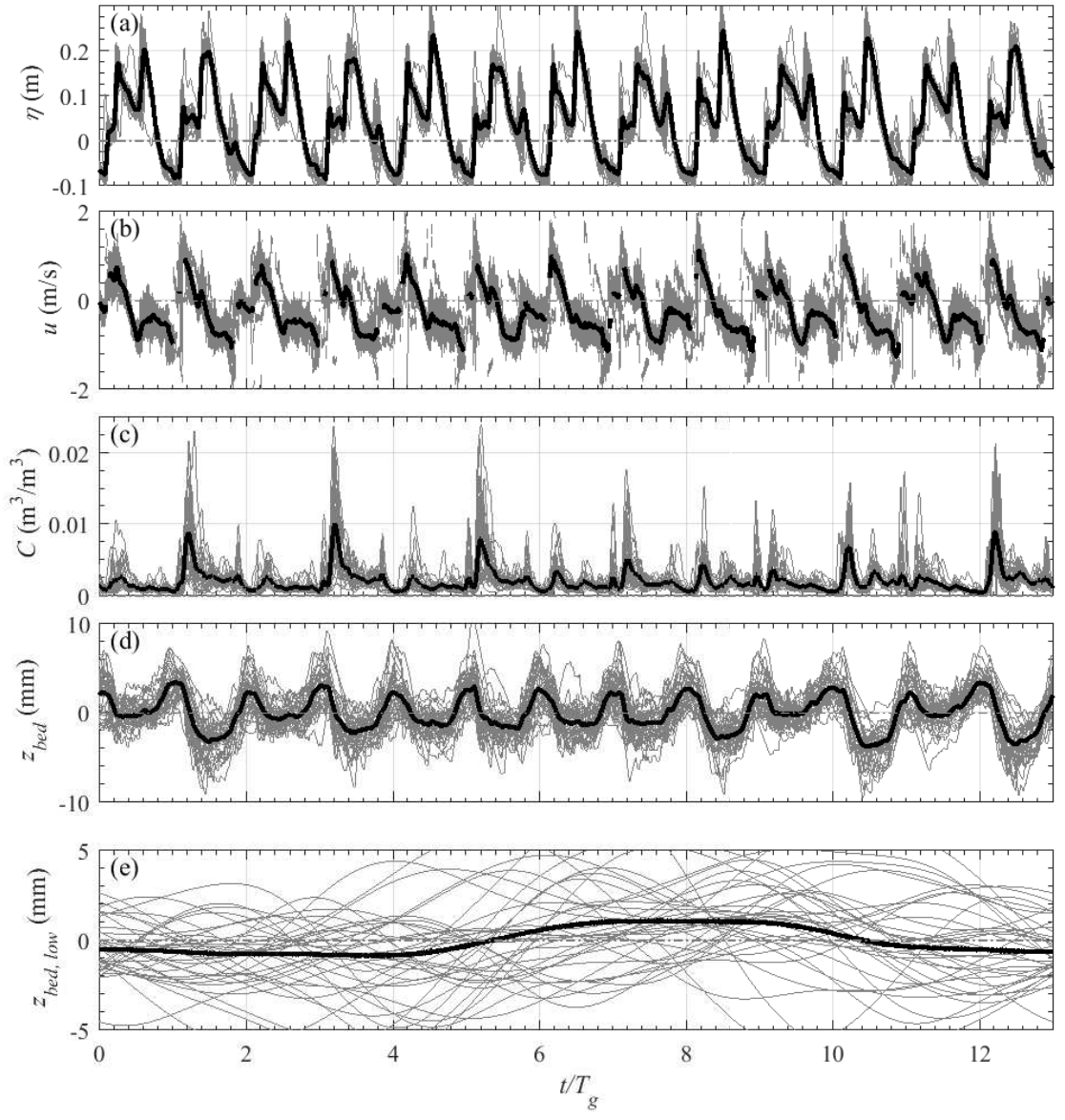

Figure A.1: Time series (grey lines) and ensemble averaged (thick black line) values of water surface elevation (a), horizontal velocity (b), suspended sediment concentration (c), high-pass filtered bed elevation obtained with $\mathrm{CCM}^{+}$probe 3 (cut-off frequency $0.02 \mathrm{~Hz}$ ) (d) and low frequency bed elevation (band-pass-filtered with cut-off frequencies 0.004$0.02 \mathrm{~Hz}$ ) (e), for condition BE1_1 and at $X=0.24 \mathrm{~m}$. 


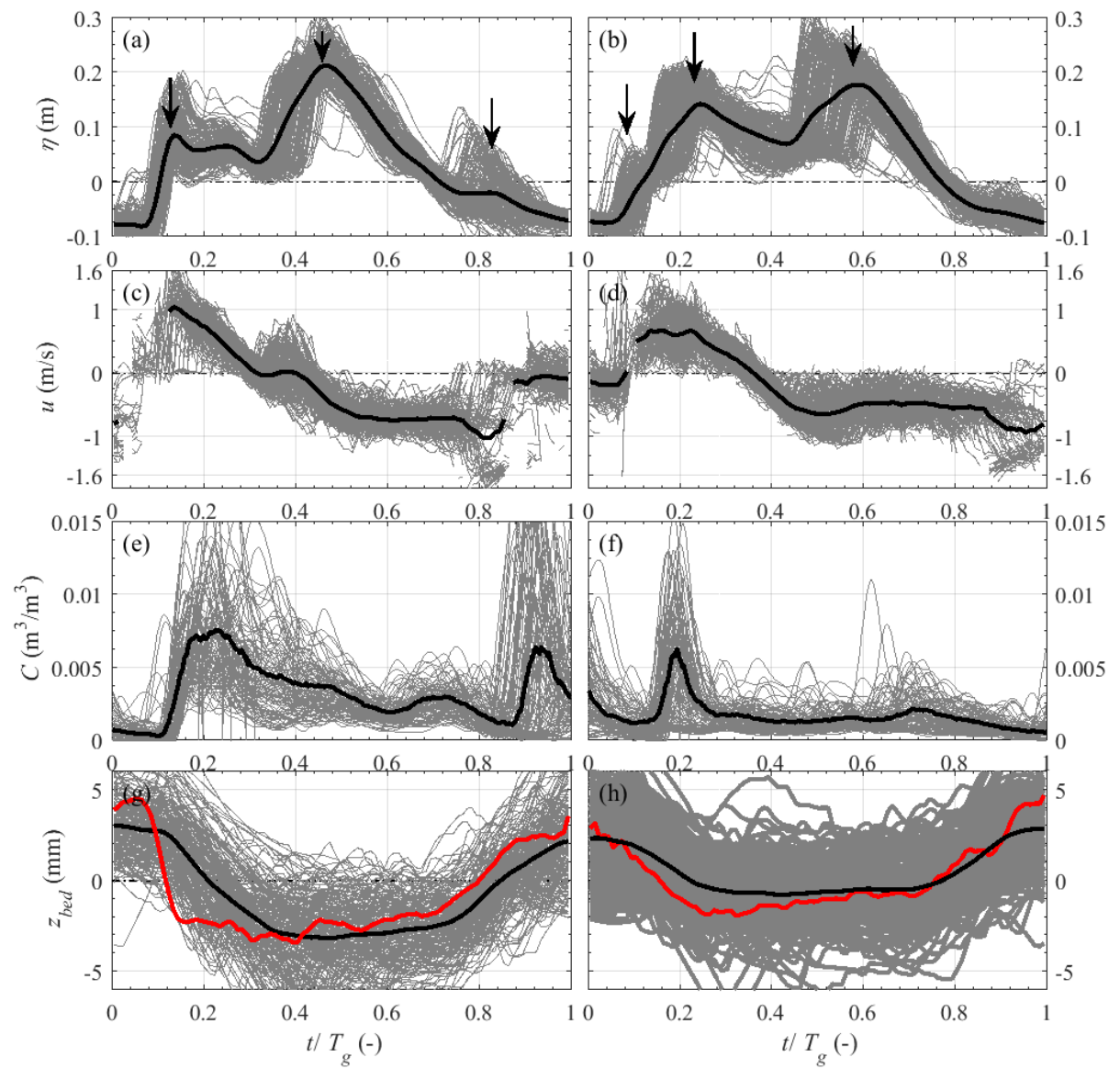

Figure A.2: Time series (grey lines) and ensemble averaged (thick black line) values of water surface elevation $(\mathrm{a}, \mathrm{b})$, horizontal velocity $(\mathrm{c}, \mathrm{d})$, suspended sediment concentration $(\mathrm{e}, \mathrm{f})$, high frequency bed elevation obtained with $\mathrm{CCM}^{+}$probe 3 high-pass filtered (cutoff frequency $0.020 \mathrm{~Hz}$ ) and pivot point position in red $(\mathrm{g}, \mathrm{h})$ for condition BE1_1 and at $X=0.24 \mathrm{~m}$ for type A (left plots) and B (right plots) swash events. 

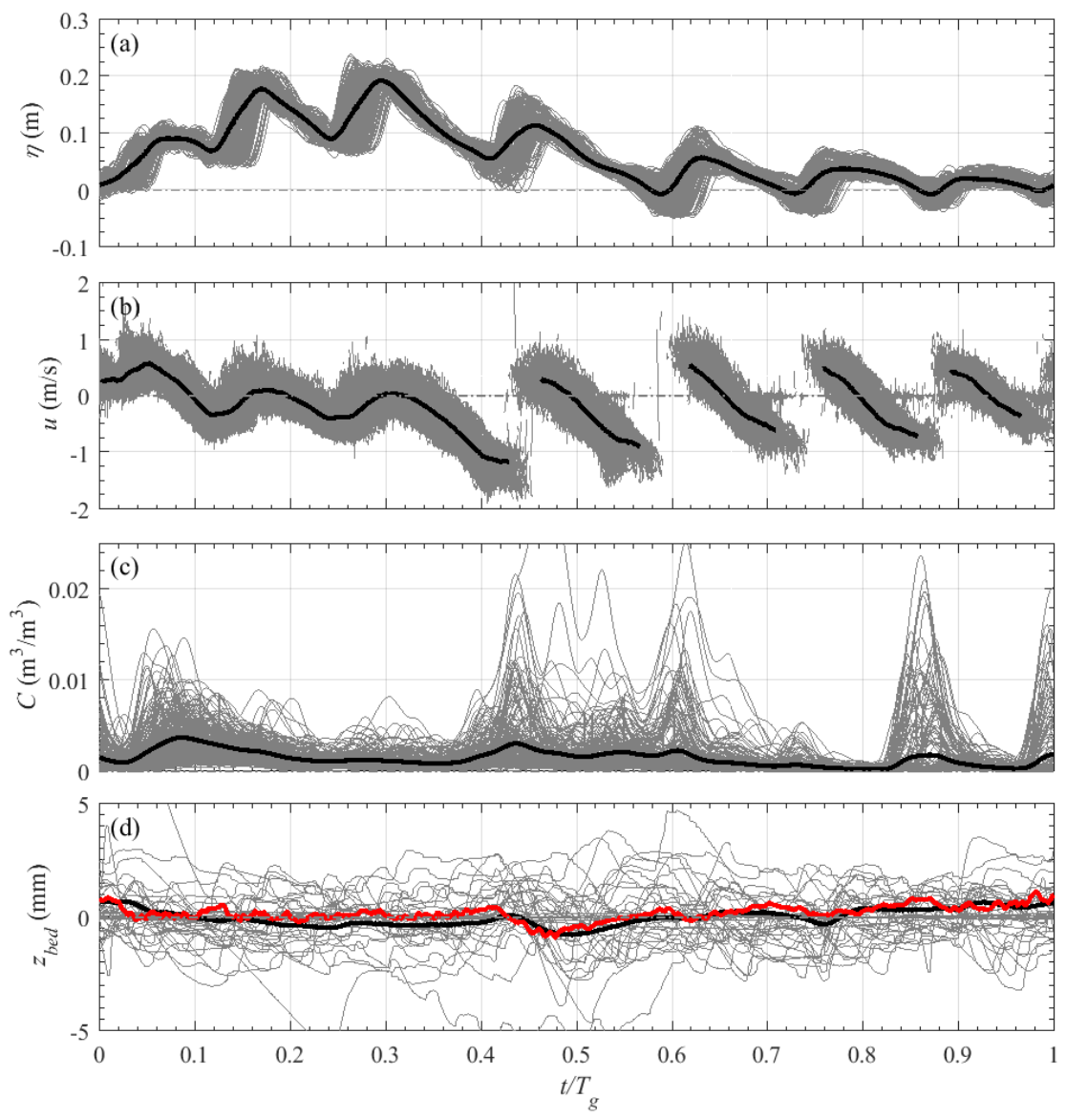

Figure A.3: Time series (grey lines) and ensemble averaged (thick black line) values of water surface elevation (a), horizontal velocity (b), suspended sediment concentration (c) and high-pass filtered bed elevation obtained with $\mathrm{CCM}^{+}$probe 3 (cut-off frequency $0.020 \mathrm{~Hz}$ ) (d) for condition BE4_2 and at $X=1.05 \mathrm{~m}$. 